
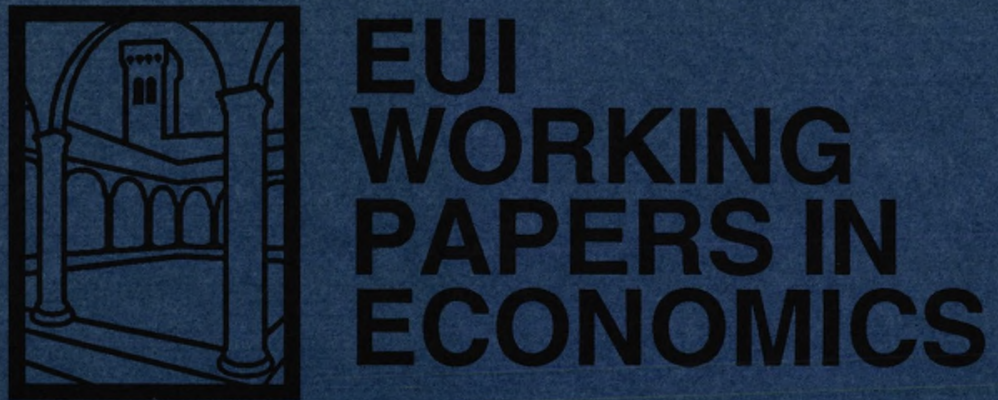

EUI Working Paper ECONo. 93/23

Statistical Inference in Calibrated Models

Fabio Canova 
EUROPEAN UNIVERSITY INSTITUTE, FLORENCE

ECONOMICS DEPARTMENT

EUI Working Paper ECO No. 93/23

Statistical Inference in Calibrated Models

FABIO CANOVA 
All rights reserved.

No part of this paper may be reproduced in any form without permission of the author.

(C) Fabio Canova

Printed in Italy in July 1993

European University Institute

Badia Fiesolana

I - 50016 San Domenico (FI)

Italy 


\title{
Statistical Inference in Calibrated Models
}

\author{
Fabio Canova * \\ Department of Economics, Brown University \\ Providence, RI 02912
}

and
Department of Economics, European University Institute
I-50016 San Domenico di Fiesole, Firenze, Italy
Canova@bf.iue.it
Telephone: (39) 55-5092-252; Fax: (39) 55-5092-202

and

CEPR

This Revision, April 1993

\begin{abstract}
This paper describes a Monte Carlo procedure to assess the performance of calibrated dynamic general equilibrium models. The procedure formalizes the choice of parameters and the evaluation of the model and provides an efficient way to conduct a sensitivity analysis for perturbations of the parameters within a reasonable range. As an illustration the methodology is applied to two problems: the equity premium puzzle and how much of the variance of actual US output is explained by a real business cycle model.
\end{abstract}

JEL Classification nos: B41, C52, C68, E32.

*I would like to thank David Backus, Larry Christiano, Frank Diebold, Javier Diaz, John Geweke, Eric Ghysels, Bruce E. Hansen, Gary Hansen, Jane Marrinan, Yaw Nyarko, Adrian Pagan, Franco Peracchi, Victor Rios, Gregor Smith, Herman van Dijk, Randall Wright for comments and the participants of seminars at Brown, European University Institute, NYU, Montréal, Rochester, Penn, University of Rome, Carlos III Madrid, Free University Bruxelles, CERGE, University of Minnesota, University of Maryland, Summer Meetings of the North American Econometric Society and the Conference on "Econometric Inference Using Simulation Techniques" for suggestions and useful discussions. 


\section{Introduction}

The current macroeconometrics literature has proposed two ways to confront general equilibrium rational expectations models with data. The first one, an estimation approach, is the direct descendent of the econometric methodology proposed 50 years ago by Haavelmo (1944). The second, a calibration approach, finds its justification in the work of Frisch (1933) and is closely linked to the computable general equilibrium literature surveyed, e.g., in Shoven and Whalley (1984).

The two methodologies share the same strategy in terms of model specification and solution. Both approaches start from formulating a fully specified general equilibrium dynamic (possibly nonlinear) model and in selecting convenient functional forms for its primitives (preferences, technology and exogenous driving forces). They then proceed to find a decision rule for the endogenous variables in terms of the exogenous and predetermined variables (the states) and the parameters. When the model is nonlinear, closed form expressions for the decision rules may not exist and both approaches rely on recent advances in numerical methods to find an approximate solution which is valid either locally or globally (see e.g. the January 1990 issue of the Journal of Business and Economic Statistics for a survey of the methods and Christiano (1990) and Dotsey and Mao (1991) for a comparison of the accuracy of the approximations).

It is when it comes to choosing the parameters to be used in the simulations and in evaluating the performance of the model that several differences emerge. The first procedure attempts to find the parameters of the decision rule that best fit the data either by maximum likelihood (ML) (see e.g. Sargent and Hansen (1980), Altug (1989) or McGratten, Rogerson and Wright (1991)) or generalized method of moment (GMM) (see e.g. Hansen and Singleton (1983) or Burnside, Eichenbaum and Rebelo (1992)). The validity of the specification is examined by testing the restrictions implied by the model, by general goodness of fit tests or by comparing the fit of two nested models. The second approach "calibrates" parameters using a set of alternative rules which includes matching long run averages, using previous microevidence or a-priori selection, and then assesses the ability of the model to fit the data with an informal distance criterion.

These differences are tightly linked to the questions the two approaches ask. Roughly speaking, the estimation approach asks the question "Given that the model is true, how true is it?" while the calibration approach asks "Given that the model is false, how false is it?" Implicit in the process of estimation is in fact the belief that the probability structure of a model is sufficiently well specified to provide an accurate description of the data. Because economic models are built with emphasis on tractability, they are often probabilistically underspecified so that measurement errors or unobservable shocks are added at estimation stage to complete their probability structure (see e.g. Sargent and Hansen (1980) or Altug (1989)). By testing the model, a researcher takes the model seriously as a data generating process (DGP) and examines what features of the specification are at variance with the data. A calibrationist takes the opposite view: the model, as a DGP, is false. That is, as 
the sample size grows, it is known that the data generated by the model will be at greater and greater variance with the observed time series. Standard testing procedures are regarded as "silly" (see Prescott (1991, p. 5)) because to estimate and test a model one has to make the Herculean assumption that the shocks driving the artificial economy are the only source of randomness in the actual data. Here an economic model is seen as an approximation to the actual DGP which need not be either accurate or realistic and should not be regarded as a null hypothesis to be statistically tested. In confronting the model with the data, a calibrationist wants to measure the magnitude of the discrepancy, indicate the dimensions where the approximation is poor and suggest modifications to obtain a better approximation.

Both methodologies have weak points. Model estimation involves a degree of arbitrariness in specifying which variables are unobservable or measured with error. In the limit since all variables are indeed measured with error, no estimation seems possible and fruitful. In addition, tests of the model's restrictions may fail to provide indications of how to alter the specification to obtain a better fit. Limitations of the calibration approach are also well known. First, the selection criterion for parameters which do not measure long run averages is very informally specified and may lead to contradictory choices. Information used in different studies may in fact be inconsistent (e.g. a parameter chosen to match labor payments from firms in national account data may not equal the value chosen to match the labor income received by households) and the range of estimates for certain parameters (e.g. risk aversion parameter) is so large that selection biases may be important. Second, although corroborating evidence on the parameters selected a-priori or not well tied down to the data is regarded as important (see e.g. Prescott (1991, p. 7) or Kydland (1992, p. 478)) and the outcomes of the simulations crucially depend on the choice of certain parameters, the sensitivity of the results to reasonable perturbations of the parameters is often not reported. Third, because the degree of confidence in the results depends on both the degree of confidence in the theory and in the underlying measurement of the parameters and because either parameter uncertainty is disregarded or, when a search is undertaken, the number of replications typically performed is small, one must resort to informal techniques to judge the relevance of the theory.

This paper attempts to eliminate some of the weaknesses of the calibration procedure while maintaining the general analytical strategy employed in calibration exercises. The focus is in trying to formalize the evaluation process and in designing procedures for meaningful robustness analysis on the outcomes of the simulations. Although proponents of this approach strongly separate the two philosophies and ascribe to calibration the heritage of "true" econometrics (see e.g. Kydland and Prescott (1991)), the procedure I suggest combines aspects of several methodologies. The technique shares features with those recently proposed by Gregory and Smith (1991a) and Kwan (1990), has similarities with stochastic simulation techniques employed in dynamic nonlinear large scale macro models (see e.g. Fair (1991)) and generalizes techniques on randomized design for strata existing in the static computable general equilibrium literature (see e.g. Harrison and Vinod (1989)). 
The idea of the technique is simple. I would like to reproduce features of actual data, which is taken to be the realization of an unknown vector stochastic process, with an "artificial economy" which is almost surely the incorrect generating mechanism for the actual data. The features one may be interested in include conditional and unconditional moments (or densities), the autocovariance function of the data, functions of these quantities (e.g. measures of relative volatility) or specific events (e.g. a recession). A model is simulated repeatedly using a Monte Carlo procedure which randomizes over both the exogenous stochastic processes and the parameters. Parameters are drawn from a density which is consistent with the frequency distribution of estimates obtained in the literature with similar general equilibrium models. I judge the validity of a model on its ability to reproduce a number of "stylized facts" of the actual economy (see Friedman (1959)). The metric used to evaluate the discrepancy of the model from the data is probabilistic. I construct the simulated distribution of the statistics of interest and, taking the actual realization of the statistic as a critical value, examine (i) in what percentile of the simulated distribution the actual value lies and (ii) how much of the simulated distribution is within two standard errors of the critical value. Extreme values for the percentile (say, below $\alpha \%$ or above $(1-\alpha) \%$ ) or a low value for the probability in the two standard error region indicates a poor fit in the dimensions examined.

The approach has several appealing features. First, it accounts for the uncertainty faced by a simulator in choosing the parameters of the model in a realistic way. Second, it has a built-in feature which automatically computes global sensitivity analysis on the support of the parameter space and allows for other forms of conditional or local sensitivity analysis. Third, it provides a general evaluation criteria and a simple and convenient metric to judge the relevance of the theory.

The paper is divided in 6 sections. The next section introduces the technique, provides a justification for the approach and describes the details involved in the implementation of the procedure. Section 3 deals with robustness analysis. Section 4 spells out the relationship with existing techniques. Two examples appear in section 5. Section 6 concludes.

\section{The Technique}

I assume that a simulator is faced with an $m \times 1$ vector of time series $\bar{x}_{t}$, which are the realizations of a vector stochastic process $\bar{X}_{t}$ and that she is interested in reproducing features of $\bar{x}_{t}$ using a dynamic general equilibrium model. $\bar{X}_{t}$ is assumed to be a Markov process with absolutely continuous but unknown distribution and moments up to the $n$-th. For the sake of presentation I assume that the unconditional distribution of $\bar{X}_{t}$ is independent of $t$ but shifts in the unconditional distribution of $\bar{X}_{t}$ at known points can easily be handled. $\bar{X}_{t}$ may include macro variables like GNP, consumption, interest rates, etc. I also assume that dynamic economic theory gives us a model expressing the endogenous variables $X_{t}$ as a function of exogenous and predetermined variables $Z_{t}$ (the states of the problem) and of 
the parameters $\beta . Z_{t}$ may include objects like the existing capital stock, exogenous fiscal and monetary variables or shocks to technologies and preferences. I express the model's functional relation as $X_{t}=f\left(Z_{t}, \beta\right)$ where $f$ is, in general, an unknown function. Under specific assumptions about the structure of the economy (e.g. log or quadratic preferences, Cobb-Douglas production function, full depreciation of the capital stock in the one-sector growth model), $f$ can be computed analytically either by value function iteration or by solving the Euler equations of the model subject to the transversality condition (see e.g. Hansen and Sargent (1980)). In general, however, $f$ can not be derived analytically from the primitives of the problem. A large body of current literature has concentrated on the problem of finding approximations which are either locally or globally close to $f$ in a given metric. ${ }^{1}$

Here I assume that either $f$ is available analytically or that one of the existing numerical procedures has been employed to obtain a functional $\mathcal{F}$ which approximates $f$ in some sense, i.e. $\left\|\mathcal{F}\left(Z_{t}, \gamma\right)-f\left(Z_{t}, \beta\right)\right\|<\epsilon$, where $\gamma=h(\beta)$ and $\|$. $\|$ is a given norm. Given the model $f$, an approximation procedure $\mathcal{F}$, a set of parameters $\beta$ and a probability distribution for $Z_{t}$, one can infer the model based probability distribution for $X_{t}$.

Let $\mathcal{G}\left(X_{t} \mid \beta, f\right)$ be the density of the $X_{t}$ vector, conditional on the parameters $\beta$ and the model $f$, let $\pi(\beta \mid \mathcal{I})$ be the density of the parameters, conditional on the information set $\mathcal{I}$ and let $\mathcal{H}\left(X_{t}, \beta \mid f, \mathcal{I}\right)$ be the joint density of simulated data and of parameters. $\mathcal{G}\left(X_{t} \mid \beta, f\right)$ is the probability that a particular path for the endogenous variables will be drawn given a parametric structure for the artificial economy and a set of parameters, while $\pi(\beta \mid \mathcal{I})$ summarizes the information on the parameters available to a simulator. For a given $\beta, X_{t}$ is random because $Z_{t}$ is random.

A generic formulation for the problem is to compute functions of simulated data and of parameters under $\mathcal{H}\left(X_{t}, \beta \mid f, \mathcal{I}\right)$, i.e. evaluating objects of the form:

$$
E\left(\mu\left(X_{t}, \beta\right) \mid f, \mathcal{I}, \mathcal{A}, \mathcal{C}\right)=\int_{\mathcal{A}} \int_{\mathcal{C}} \mu\left(\beta, X_{t}\right) \mathcal{H}\left(X_{t}, \beta \mid \mathcal{I}, f\right) d \beta d X_{t}
$$

where $\mu\left(X_{t}, \beta\right)$ is the vector of functions, which may include moments and other statistics of the simulated data, $\mathcal{A} \subset \mathcal{B}$ and $\mathcal{B}$ is the parameter space and $\mathcal{C}$ is the support of the exogenous variables. Let $h\left(\bar{x}_{t}\right)$ be the corresponding vector of functions of the actual data.

The problem of the fit of the model can be summarized with the following question: how likely is the model to generate $h\left(\bar{x}_{t}\right)$ ? To answer note that from (1) we can compute probabilities of the form $P\left(\mu\left(X_{t}, \beta\right) \in D\right)$, where $D$ is a bounded set. To do this choose, for example, the m-th component of $\mu$ to be $\mu_{m}\left(X_{t}, \beta\right)=\chi\left(X_{t}, \beta\right.$ : $\left.\mu\left(X_{t}, \beta\right) \in D\right)$ where $\chi$ is the indicator function, i.e. $\chi\left(\mu\left(X_{t}, \beta\right) ; D\right)=1$ if $\mu\left(X_{t}, \beta\right) \in$ $D$ and zero otherwise. From (1) one can also find a value $\tilde{h}$ satisfying $P\left[\mu\left(X_{t}, \beta\right) \leq\right.$ $\tilde{h}]=v$ for any given $v$, by appropriately selecting the indicator function.

\footnotetext{
${ }^{1}$ These include linear or $\log$-linear expansions of $f$ around the steady state (Kydland and Prescott (1982), and King, Plosser and Rebelo (1988)), backward solving methods (Sims (1984), Novales (1990)), global functional expansions in polynomials (Marcet (1992), Judd (1989)), piecewise linear interpolation methods (Coleman (1989), Baxter (1991)) and quadrature techniques (Tauchen and Hussey (1991)).
} 
Model evaluation then consists of several types of statements which are essentially interchangeable and differ only in the criteria used to measure distance. First, one can compute $P\left[\mu\left(X_{t}, \beta\right) \leq h\left(\bar{x}_{t}\right)\right]$. In other words, we can examine the likelihood of an event (the observed realization of the summary statistics in the actual data) from the point of view of the model. Extreme values for this probability indicate a poor "fit" in the dimensions examined. Alternatively, if one can measure the sampling variability of $h\left(\bar{x}_{t}\right)$, she can then choose the set D to include the actual realization of $h\left(\bar{x}_{t}\right)$ plus one or two standard deviations and either check whether $\tilde{h}$ is in $\mathrm{D}$ and/or calculate $P\left[\mu\left(X_{t}, \beta\right) \varepsilon D\right]$.

\subsection{An Interpretation}

The proposed framework of analysis lends itself to simple Bayesian interpretation. In this case $\pi(\beta \mid \mathcal{I})$ is the prior on the parameters and, although nonstandard, it has some relationship with the prior used in the empirical Bayes literature (see e.g. Harsaee (1987)). The function $\mathcal{G}$ is entirely analogous to a classical likelihood function for $X_{t}$ in a standard regression model. The difference is that $\mathcal{G}$ need not be the correct likelihood for $X_{t}$. Then (1) is the conditional expectation of $\mu\left(X_{t}, \beta\right)$ under the joint density of the model and parameters and it is proportional to the posterior mean of $\mu$ under the assumption that the marginal density of $X_{t}$ is fixed.

There is also a less orthodox interpretation of the approach which exchanges the role of $\pi(\beta \mid \mathcal{I})$ and $\mathcal{G}$ and is nevertheless reasonable. In this case $\mathcal{G}$ is the prior and represents the a-priori degree of confidence posed by the researcher on the model given the parameters while $\pi(\beta \mid \mathcal{I})$ summarizes the information contained in the data. Then (1) is a "posterior" statement about the model once empirical evidence on the parameters is taken into account.

\subsection{Implementation}

There are four technical implementation issues which deserve some discussion. The first concerns the computation of integrals like those in (1). When the $\left(\beta, Z_{t}\right)$ vector is of high dimension simple discrete grid approximations, spherical or quadrature rules quickly become unfeasible since the number of function evaluations increases exponentially with the dimension of $\beta$ and $Z_{t}$. In addition, unless the contours of $\mathcal{H}\left(X_{t}, \beta \mid \mathcal{I}, f\right)$ are of ellipsoidal forms, grid evaluations may miss most of the action of this density. There are several feasible alternatives: one is the Monte Carlo procedure described in Geweke (1989), another is the data augmentation procedure of Tanner and Wong (1987), a third the "Gibbs sampler" discussed in Gelfand and Smith (1990). Finally, one could use one of the quasi-random procedures proposed by Niederreiter (1988).

In this paper I adopt a Monte Carlo approach. After drawing with replacement iid $\beta$ vectors and $Z_{t}$ paths, I substitute sums over realizations for the integrals appearing in (1) and appeal to the central limit theorem for functions of iid random 
variables to show that

$$
\frac{1}{N} \sum_{i=1}^{N} \mu_{i}\left(X_{t}, \beta\right) \stackrel{\text { a.s. }}{\longrightarrow} E\left(\mu\left(X_{t}, \beta\right)\right)
$$

where $N$ is the number of replications. Note that, although $\mathcal{H}$ is in general unknown, sampling from $\mathcal{H}$ can be conveniently accomplished by simulating the model repeatedly for random $\left(Z_{t}, \beta\right)$, i.e. randomly drawing exogenous forces, selecting a parameter vector and using the decision rule to compute time paths for $X_{t}$.

Second, since in most cases the function $f$ is unknown, $\mathcal{G}$ itself becomes unknown and the direct computation of (1) is unfeasible. If the approximation $\mathcal{F}$ to $f$ is accurate, one could simply neglect the error and proceed using $\mathcal{J}\left(X_{t} \mid \beta, \mathcal{F}\right)$ in place of $\mathcal{G}\left(X_{t} \mid \beta, f\right)$. However, since only little is known about the properties of approximation procedures and some have only local validity (see e.g. Christiano (1990) and Dotsey and Mao (1991)), one may want to explicitly account for the existence of an approximation error in conducting inference. In this case, following Geweke (1989), one would replace (1) with:

$$
E\left(\mu\left(X_{t}, \beta\right) \mid f, \mathcal{I}, \mathcal{A}, \mathcal{C}\right)=\int_{\mathcal{A}} \int_{\mathcal{C}} \mu\left(X_{t}, \beta\right) \mathcal{J}\left(X_{t}, \beta \mid \mathcal{I}, \mathcal{F}\right) \omega(\beta, f, \mathcal{F}) d \beta d X_{t}
$$

where $\omega(\beta, f, \mathcal{F})$ are weights which depend on the "true" density $\mathcal{G}\left(X_{t}, \beta \mid \mathcal{I}, f\right)$ and on the approximation density $\mathcal{J}\left(X_{t}, \beta \mid \mathcal{I}, \mathcal{F}\right)$. Thus, the approximation problem can be posed in terms of choosing a procedure which makes the weights as close as possible to 1 .

Third, one must specify a density for the parameters of the model. One could choose $\pi(\beta \mid \mathcal{I})$ to be based on one specific data set and use the asymptotic distribution of a GMM estimator (as in Burnside, Eichenbaum and Rebelo (1992)), of a simulated method of moments (SMM) estimator (as in Canova and Marrinan (1991)), or of a ML estimator of $\beta$ (as in Phillips (1991)). The disadvantage of these procedures is that such a density does not necessarily reflect the cross-study information available to a simulator. As Larry Christiano has pointed out to me, once a researcher chooses the moments to match, the uncertainty surrounding estimates of $\beta$ is small. The true uncertainty lies in the choice of moments to be matched and in the sources of data used to compute estimates.

In this paper $\pi(\beta \mid \mathcal{I})$ is selected so as to summarize all existing information. Depending on the problem examined, there are several ways of doing so. One is to count estimates of $\beta$ previously obtained in the literature using comparable model specifications and construct $\pi(\beta \mid \mathcal{I})$ by smoothing the resulting histogram. For example, if one of the elements of the $\beta$ vector is the risk aversion parameter, by counting estimates obtained over the last 15 years from fully specified general equilibrium models and smoothing the resulting histogram, one would obtain a truncated (below zero) bell-shaped density, centered around two and very small mass above 4. Another way is to take what the profession regards as a reasonable range for $\beta$ ("I do not know the exact value of $\beta$, but it cannot be greater than $\beta_{1}$ or smaller than $\beta_{2}$ ") and assume more or less informative densities on the support depending 
on available estimates. If theoretical arguments suggest that the maximum range for, e.g., the risk aversion parameter is $[0,20]$, one can put higher weights on the interval $[1,3]$ where most of the estimates lie. If for some parameters previous econometric evidence is scant, measurement is difficult or there are no reasons to expect that one value is more likely than others, one could assume uniform densities on the chosen support.

Available estimates of $\beta$ are not necessarily independent (the same data set is used in many cases) and some are less reliable than others. Non-independent estimates are legitimate candidates to enter the information set as long as they reflect sampling variability or different estimation techniques. The influence of less reliable estimates can be discounted by giving them a smaller weight in constructing histograms.

Finally, in many applications the joint density of the parameter vector can be factored into the product of lower dimensional densities. If no relationship across estimates of the various parameters exists, $\pi(\beta \mid \mathcal{I})$ is the product of univariate densities. If estimates of certain parameters are related (e.g. in the case of the discount factor and the risk aversion parameter in asset pricing models), one can choose multivariate densities for these dimensions and maintain univariate specifications for the densities of the other parameters.

\section{Robustness Analysis}

If one adopts a Monte Carlo approach to compute (1), an automatic and efficient global sensitivity analysis is performed on the entire support of the parameter space as a by-product of the simulations. Sensitivity analysis, however, can take other more specific forms. For example, one may be interested in examining how likely $\mu\left(X_{t}, \hat{\beta}\right)$ is to be close to $h\left(\bar{x}_{t}\right)$ where $\hat{\beta}$ is a specific value of $\beta$. This would be the case for example, if $\beta$ includes parameters which can be manipulated by the government and $h\left(\bar{x}_{t}\right)$ is the current account balance of that country. In this case one could choose a path for $Z_{t}$ and analyze the conditional distribution of $X_{t}$ for the selected value(s) of $\beta$. Alternatively, one might wish to assess the maximal variation in $x_{t}$ or $\mu\left(X_{t}, \beta\right)$ which is consistent, say, with $\beta$ being within two standard error bands of a particular value. Here one chooses a path for $Z_{t}$ and constructs paths for $X_{t}$ for draws of $\beta$ in the range. Finally, one may be interested in knowing which dimensions of $\beta$ are responsible for features of the distribution of $\mu\left(X_{t}, \beta\right)$. For example, it may be that the simulated distribution for $\mu$ has a large spread or fat tails and it is important to know whether technology or preference parameters are responsible for this feature. In this case one would partition $\beta$ into $\left[\beta_{1}, \beta_{2}\right]$ and compute the simulated distribution of $\mu\left(X_{t}, \beta_{1} \mid \hat{\beta}_{2}\right)$ where $\hat{\beta}_{2}$ is a prespecified value.

All of the above cases examine the robustness of the results to changes in the parameters within their support. In some cases the sensitivity of the results to local perturbations needs to be examined. For example, one may be interested in determining how robust the simulation results are to changes of the parameters in 
a small neighborhood of a calibrated vector. To undertake this type of analysis one can take a numerical version of the average derivative of $\mu\left(X_{t}, \beta\right)$ in the neighborhood of a calibrated vector (see Pagan and Ullah (1991)). Because global and local analysis aim at measuring the sensitivity of the outcomes to perturbations of different size they provide complementary information and should be both performed as specification diagnostics for simulated models.

\section{A Comparison with Existing Methodologies}

The framework of analysis set up in section 2 is general enough to include both simulation with estimation and simulation with calibration as special cases. To show this it is convenient to note that, in general, there is an exact relation between the $X_{t}$ and the $Z_{t}$ once $\beta$ is selected and that randomness in $X_{t}$ depends on the randomness in $Z_{t}$ and in $\beta$ so that the joint density $\mathcal{H}\left(X_{t}, \beta \mid \mathcal{I}, f\right)$ is a deterministic transformation of $Q\left(Z_{t}, \beta \mid \mathcal{I}, f\right)=\pi(\beta \mid \mathcal{I}) \kappa\left(Z_{t} \mid f\right)$ where $\kappa\left(Z_{t} \mid f\right)$ is the density for the exogenous processes. The two procedures can then be recovered by imposing restrictions on the shape and the location of $\pi(\beta \mid \mathcal{I})$ and in some cases also on the shape and the location of $\kappa\left(Z_{t} \mid f\right)$.

Calibration exercises impose a point mass for $\pi(\beta \mid \mathcal{I})$ on a particular value of $\beta$ (say, $\hat{\beta}$ ). One interpretation of this parameter selection procedure is that a simulator is perfectly confident in the vector $\beta$ used and does not worry about the cross-study or time series uncertainty surrounding estimates of $\beta$. Note that when the density of $\beta$ is a singleton the marginal and the conditional density of $X_{t}$ are identical. In certain situations a path for the vector of exogenous variables is also selected in advance either by drawing only one realization from their distribution or by choosing a $z_{t}$ on the basis of extraneous information, e.g., inputting Solow's residuals in the model, so that $\kappa\left(Z_{t} \mid f\right)$ is also a singleton. In this instance, the marginal for $X_{t}$ has a point mass and because the likelihood of the model to produce any event is either 0 or 1 , one must resort to informal techniques to assess the discrepancy of simulated and actual data. In some studies the randomness in $Z_{t}$ is explicitly considered, repeated draws for the exogenous variables are made for a fixed $\beta$ and moments of the statistics of interest are computed by averaging the results over a small number of simulations (see, e.g., Backus, Gregory and Zin (1989)).

Simulation exercises with estimation of the parameters are also special cases of the above framework. Here $\pi(\beta \mid \mathcal{I})$ has a point mass at $\beta^{*}$, where $\beta^{*}$ is either the GMM estimator, the SMM estimator (see Lee and Ingram (1991)) or the simulated quasi maximum likelihood (SQML) estimator of $\beta$ (see Smith (1992)). Simulations are performed by drawing one realization from $\mathcal{G}\left(X_{t} \mid \beta^{*}, f, \mathcal{I}\right)$ and standard errors for $\mu\left(X_{t}, \beta\right)$ are computed using the asymptotic standard errors of $\beta^{*}$ and the functional form for $\mu$. In some cases, $\pi(\beta \mid \mathcal{I})$ is the asymptotic distribution of one of the above estimators (as in Canova and Marrinan (1991)). In this case, simulations are performed by drawing from $\mathcal{G}\left(X_{t} \mid \beta^{*}, f, \mathcal{I}\right) \pi\left(\beta^{*} \mid \mathcal{I}\right)$ and using measures of discrepancy like the ones proposed here. 
In assessing the model's performance procedures where parameters are estimated have two advantages over calibration. First, they allow formal statements on the likelihood of selected parameter values to reproduce the features of interest. For example, if a four standard error range around the point estimate of the AR(1) parameter for the productivity disturbance is $[.84, .92]$, then it is highly unlikely (with probability higher than $99 \%$ ) that a unit root productivity disturbance is needed to match the data. Second, they provide a setup where sensitivity analysis can easily be undertaken (although not often performed).

Such procedures also have two major shortcomings. First, they impose a strong form of ignorance which does not reflect available a-priori information. The vector $\beta$ may include meaningful economic parameters which can be bounded on the basis of theoretical arguments. A risk aversion parameter which is negative or in excess of, say 20 , is theoretically unacceptable, but the range of possible $\beta$ with GMM, SMM or SQML procedures is $[-\infty, \infty]$. By appropriately selecting a hypercube for their densities a researcher can make "unreasonable" parameter values unlikely and avoid a-posteriori adjustments. Second, simulations may not constitute an independent way to validate the model because the parameters are obtained from the same data set which later will be used to compare results.

Mixed calibration and GMM estimation strategies have recently been employed by, e.g., Burnside, Eichenbaum and Rebelo (1992) and mixed calibration and estimation by simulation strategies by, e.g., Canova and Marrinan (1991). Here some parameters are fixed using extraneous information while others are formally estimated using moment (or simulated moment) conditions. Although mixed strategies allow a more formal evaluation of the properties of the model than pure calibration procedures, they face two problems. First, as in the case when the parameters are all selected using GMM, SMM and SQML procedures, the evaluation of the model is problematic because standard errors for the statistics of interest are based on one data set and do not reflect the potential range of outcomes of the model once the cross-study uncertainty faced by a simulator is taken into account. Second, as Gregory and Smith (1989) have pointed out, the small sample properties of estimators obtained from mixed strategies may be far from reasonable unless calibrated parameters are consistent estimators of the true parameters. When this condition is not satisfied, estimates of the remaining parameters are sensitive to errors in pre-setting and forcing a close match of simulated and actual moments generates misleading inference.

The Monte Carlo methodology to model evaluation proposed here is related to those of Gregory and Smith (1991a) and Kwan (1990) but several difference need to be emphasized. First, Gregory and Smith take the model as a testable null hypothesis while this is not the case here. Second, they do not account for parameter uncertainty in evaluating the outcomes of the model. Third, because they take a calibrated version of the model as the "truth", they conduct sensitivity analysis inefficiently, by replicating experiments for different calibrated values of the parameters. Kwan (1990) allows for parameter uncertainty in his simulation scheme but following an orthodox Bayesian approach, he chooses a subjective prior 
density for the parameters. In addition, he evaluates the outcomes of the model in relative terms, by comparing two alternative specifications using a posterior-odds ratio: a model is preferred relative to another if it maximizes the probability that the simulated statistics are in a prespecified set.

The procedure for sensitivity analysis proposed extends the approach that Harrison and Vinod (1989) used in deterministic computable general equilibrium models. The major difference is that, in a stochastic framework parameter uncertainty is only a part of the randomness entering the model and the uncertainty characterizing the exogenous processes is an important and intrinsic component of randomness of the outcomes.

To conclude, one should mention that parallel to the literature employing Monte Carlo methods to evaluate a simulated model, there is also a branch of the literature which uses more standard tools to examine the fit of calibrated models. This is the case, e.g., of Watson (1990), Smith (1992) and Canova, Finn and Pagan (1992) which assess the relevance of theoretical models with regression $R^{2}$ 's, tests based on restricted and unrestricted VARs and encompassing procedures.

\section{Two Examples}

\subsection{The Equity Premium Puzzle}

Merha and Prescott (1985) suggest that a complete markets pure exchange asset pricing model cannot simultaneously account for the average risk free rate and the average equity premium experienced by the US economy over the sample 1889-1978 with reasonable values of the risk aversion parameter and of the discount factor.

The model they consider is a frictionless pure exchange Arrow-Debreu economy with a single representative agent, one perishable consumption good produced by a single productive unit or a "tree" and two assets, an equity share and a risk free asset. The tree yields a random dividend each period and the equity share entitles its owner to that dividend in perpetuity. The risk free asset entitles its owner to one unit of the consumption good in the next period only. The agent maximizes:

$$
E_{0} \sum_{t=0}^{\infty} \beta^{t}\left[\frac{c_{t}^{1-\omega}-1}{1-\omega}\right]
$$

subject to :

$$
c_{t}=y_{t} e_{t-1}+p_{t}^{e}\left(e_{t-1}-e_{t}\right)+f_{t-1}-p_{t}^{f} f_{t}
$$

where $c_{t}$ is consumption and $y_{t}$ is the tree's dividend, $p_{t}^{e}$ and $p_{t}^{f}$ are the prices of the equity and the risk free asset and $e_{t}$ and $f_{t}$ are the agent's equity and risk free asset holding at time $t, E_{0}$ is the mathematical expectation operator conditional on information at time zero, $\beta$ is the subjective discount factor and $\omega$ is the risk aversion parameter. Production evolves according to:

$$
y_{t+1}=x_{t+1} y_{t}
$$


where $x_{t}$, the gross growth rate, follows a two state ergodic Markov chain with probability $P\left(x_{t+1}=x_{j} \mid x_{t}=x_{i}\right)=\phi_{i j}$. Defining the states of the problem as $(c, i)$ when $y_{t}=c$ and $x_{t}=\lambda_{i}$, the period $t$ equilibrium asset prices can be expressed as (see Merha and Prescott (1985, p.152-153)):

$$
\begin{aligned}
& p^{e}(c, i)=\beta \sum_{j=1}^{2} \phi_{i, j}\left(\lambda_{j} c\right)^{-\omega}\left[p^{e}\left(\lambda_{j} c, j\right)+\lambda_{j} c\right] c^{\omega} \\
& p^{f}(c, i)=\beta \sum_{j=1}^{2} \phi_{i, j} \lambda_{j}^{-\omega}
\end{aligned}
$$

When the current state is $(c, i)$, the expected equity return and the risk free rate are:

$$
\begin{aligned}
R_{i}^{e} & =\sum_{j=1}^{2} \phi_{i, j}\left(\frac{p^{e}\left(\lambda_{j} c, j\right)+\lambda_{j} c}{p^{e}(c, i)}-1\right) \\
R_{i}^{f} & =\frac{1}{p^{f}(c, i)}-1
\end{aligned}
$$

The unconditional (average) expected returns on the two assets are $R^{e}=\sum_{j=1}^{2} \pi_{i} R_{i}^{e}$, $R^{f}=\sum_{j=1}^{2} \pi_{i} R_{i}^{f}$, while the average equity premium is $E P=R^{e}-R^{f}$, where $\pi_{i}$ are the Markov chain stationary probabilities, satisfying $\pi=\phi^{T} \pi$ and $\sum_{i} \pi_{i}=1$ where $\phi^{T}=\phi_{j, i}$.

Merha and Prescott specified the two states for consumption (output) to be $\lambda_{1}=1+\mu+\nu ; \lambda_{2}=1+\mu-\nu$ and restricted $\phi_{1,1}=\phi_{2,2}=\phi$ and $\phi_{1,2}=\phi_{2,1}=1-\phi$. They calibrated the three technology parameters so that the mean, the standard error and the AR(1) coefficient of the model's consumption match those of the growth rate of annual US consumption over the period 1889-1978 and searched for combinations of the preference parameters $(\beta, \omega)$ which lie in a prespecified interval to obtain values for the risk free rate and the equity premium. Given that the average, the standard error and the $\mathrm{AR}(1)$ coefficient of annual growth rate of US consumption are $1.018,0.036$ and -0.14 , the implied values of $\mu, \nu$ and $\phi$ are 0.018 , 0.036 and 0.43 , respectively. The range for $\omega$ was selected a-priori to be $[0,10]$ and this choice was justified citing a number of empirical estimates of this parameter (see Merha and Prescott (1985, p. 154). The range for $\beta$ was chosen to be $[0,1]$, but simulations which produced a risk free rate in excess of $4 \%$ were eliminated on the ground that $4 \%$ constitutes an upper bound for the average real risk free rate which is consistent with historical experience. They then compared the outcomes of the model with the average real risk free rate of $0.80 \%$ and the average equity premium of $6.18 \%$ obtained for the US economy for the period $1889-1978$. The puzzle is that the largest equity premium generated by the model is $0.35 \%$, which occurred in conjunction with a real risk free rate of about $4 \%$.

Two hidden assumptions underlie Merha and Prescott's procedure. First, they presumably believe that technology parameters can be tightly estimated while there is uncertainty in the exact value of the preference parameters and an interval estimate is more reasonable. Consequently, while the sensitivity of the results is 
explored to variations in $\beta$ and $\omega$ within the range, no robustness check is made for perturbations of the technology parameters. Second, by providing only the largest value generated, they believe that it is a sufficient statistic to pose the puzzle.

Here I repeat their exercise with three tasks in mind: (i) conduct sensitivity analysis to perturbations within a reasonable range in all five parameters of the model, (ii) describe the distribution of possible outcomes obtained with various specifications of the model, evaluate the magnitude of the discrepancy from the data in a probabilistic way and suggest which dimensions of the parameter space are responsible for features of the distribution of outcomes, (iii) evaluate the contribution of two alleged solution to the equity premium puzzle which have been proposed in the literature.

To choose the ranges for the five parameters of the model I follow Merha and Prescott approach and select them so that they include all the existing estimates obtained with similar model specifications. On these supports I choose the joint density to be the product of 5 univariate densities and specify each univariate density to be a smoothed version of the frequency distribution of estimates existing in the literature. The densities and their support are reported in table 1. The range for $\omega$ is the same as that of Merha and Prescott and the chosen $\chi^{2}$ density has a mode at 2 , where most of the estimates of this parameter lie, and a low mass (smaller than $5 \%$ ) for values exceeding 6 . The range for $\beta$ reflects the results of several estimation studies which obtained values for the steady state real interest rate in the range [-0.005, 0.04] (see e.g. Altug (1989), Dunn and Singleton (1986) or Hansen and Singleton (1983)) and of several simulation studies which imply a steady state real interest rate in the range [0, 0.05] (see e.g. Kandel and Stambaugh (1990) or Merha and Prescott (1985)). The density for $\beta$ is skewed to express the idea that a steady state real interest rate of $2-3 \%$ or lower is more likely than a steady state interest rate in excess of $4 \%$. Note that, although I assume independent densities over $\beta$ and $\omega$, many estimates of these two parameters are not independent. However, the rank correlation coefficient across pairs of estimates is small and none of the results I present depends on this simplifying assumption.

To provide a density for $\mu, \nu$ and $\phi$ I experimented with two procedures. The first one, which is used in the basic experiment, involves taking the 10 subsample estimates of the mean, of the standard error and of the AR(1) coefficient of the growth rate of consumption over 10 year samples contained in Merha and Prescott (1985, p. 147) as different estimates of reasonable consumption processes and then constructing a uniform discrete density over these triplets. The second involves dividing the growth rates of consumption over the 89 years of the sample in two states (above and below the mean), estimating for each state the standard deviation of the mean, of the standard deviation and of the AR(1) coefficient of the growth rate of consumption and directly inputting these estimates into estimates into the model. In this case simulations are performed by assuming a joint normal density for the mean, the standard deviation and AR(1) coefficient in each state centered around the point estimates of the parameters and support within two standard errors.

Figures 1-4 present scatterplots of the simulated pairs $\left(R^{f}, E P\right)$ when 10000 
simulations are performed. I summarize the features of the joint distributions in table 1 using the first four moments, the median, the mode, the $90 \%$ ranges and the largest values. To evaluate the discrepancy of the model from the data I report three numbers for each distribution: the probability that the model generates values for $\left(R^{f}, \mathrm{EP}\right)$ which fall within a two standard deviation band of the actual estimate, the probability that the simulated pairs are in each of the four quadrants of the space delimited by the actual values of $\left(R^{f}, \mathrm{EP}\right)$ and the percentile contour of the simulated distribution where the actual value of $\left(R^{f}, \mathrm{EP}\right)$ lies.

Figure 1 reports the results obtained with the Merha and Prescott specification. It is immediate to check that, for a value of the risk free rate not exceeding $4 \%$, the value of the equity premium is very small and equal to 0.0030 , confirming Merha and Prescott's conclusion. It is also easy to see that the distribution of possible outcomes is essentially uniform and that the mode of the joint distribution is at $(0.110,0.0094)$. Finally, the probabilistic measures of discrepancy suggest that a large portion of simulations produce values of $\left(R^{f}, \mathrm{EP}\right)$ which are in the upper left quadrant. Also, about $73 \%$ of the simulations produce pairs which are within a classical $95 \%$ ball around the point estimates we see in the data and that the actual value is outside the 99 percentile contour.

Figure 2 reports the plots for the basic specification of the model. Also in this case, if we set a $4 \%$ upper bound to the risk free rate, the maximum equity premium generated is only 0.0038 . The probability that the model generates values in a ball centered around the actual values of $\left(R^{f}, E P\right)$ is $81.4 \%$. In addition, in $100 \%$ of the cases the simulated risk free rate exceeds the actual value and the simulated equity premium is below the actual value, while the actual values lies outside the 99 percentile contour.

To examine whether the selection of the distribution for the technology parameters has any effect on the results, I also conducted simulations using the parameters selected by the second procedure previously described. No substantial changes emerge. For example, the probability that the model generates values in a ball centered around the actual values of $\left(R^{f}, \mathrm{EP}\right)$ is $80.3 \%$ and the maximum value for EP compatible with a risk free rate not exceeding $4 \%$ is 0.0025 .

Several conclusions can be drawn from this first exercise. First, even after taking into account the uncertainty surrounding estimates of the technology parameters, the puzzle remains regardless of the way it is defined (means, medians, modes or maximum values): the model cannot generate pairs $\left(R^{f}, \mathrm{EP}\right)$ which match the values we find in the data. Second, the simulated distributions are bimodal, highly left skewed and have a fat left tail indicating that lower than average values are more probable and that very small values have nonnegligible probability. Third, the simulated risk free rate is always in excess of the actual one, a result that Weil (1990) has termed the risk free rate puzzle. Fourth, while the model fails to generate values for $\left(R^{f}, \mathrm{EP}\right)$ which replicate the historical experience, in more than $80 \%$ of the simulations it produces pairs which are within two standard deviation bands of the actual values.

Next, I conducted two exercises to examine the contribution of the modifica- 
tions suggested by Kocherlakota (1990), Benninga and Protopapadakis (1990) and by Rietz (1988) to the solution of the puzzle. The first experiment allows the discount factor $\beta$ to take on values greater than 1 . The justification is that in a growing economy a reasonable value for the steady state real interest rate can be obtained even with $\beta$ greater than 1 . In this experiment I still maintain the truncated normal density for $\beta$ used in the baseline case but I increase the upper value for its range to 1.04 and allow about $10 \%$ of the density in the region above 1.0.

The second experiment assumes the presence of a third unlikely crash state where consumption falls substantially. ${ }^{2}$ The justification for including a third state is that in the Great Depression consumption fell substantially and excluding such a state may have important implications on the results (a conclusion denied by Merha and Prescott (1988)). In this specification there are two new parameters which cannot be measured from available data $(\zeta$, the probability of a crash state and $\xi$, the percentage fall in consumption in the crash state). Rietz (1988) searches over the a-priori ranges of $[0.0001,0.2]$ and $\left[\frac{\mu}{1+\mu}, 1-\frac{\nu}{1+\mu}\right]$ and checks what is the maximum simulated equity premium that the model generates when we restrict the risk free rate to be below $4 \%$. I maintain these ranges in my experiment and assume on these supports an exponential density for $\zeta$ and a three point discrete density for $\xi$ which summarizes the three cases examined by Rietz (1988) (see table 1).

Allowing the discount factor to take on values greater than 1 goes a long way in reducing the discrepancy of the model from the data (see figure 3) since it shifts the univariate distribution of $R^{f}$ down (the minimum and maximum values of $R^{f}$ are now $(-0.084,0.092)$. For example, the probability that the model generates values in a ball centered around the actual values of $\left(R^{f}, \mathrm{EP}\right)$ is now $85.7 \%$ and in only $7.4 \%$ of the cases is the risk free rate in excess of the value found in the data. Because of this shift in the simulated distribution of $R^{f}$, the maximum value of EP consistent with a risk free rate below $4 \%$ is 0.031 , a value with a standard error of 0.11. Despite these differences, the location and the shape of the univariate distribution of EP changes very little. Hence, although the equity premium puzzle is "solved" when defined in terms of the maximum simulated EP consistent with a maximum risk free rate of $4 \%$, it is still very evident when we look at the univariate distributional properties of simulated EP.

The second modification appears to be much less successful (see figure 4). It does shift the univariate distribution for EP to the right (the median, mode and mean are $0.010,0.035,0.109$ ) and increases the dispersion of EPs but it achieves this at the cost of shifting the distribution of $R^{f}$ toward unrealistic negative values (the mean is -0.15 , the lowest value -0.99 and the $90 \%$ range $[-0.940,0.068]$ ) and of scattering the simulated values for $\left(R^{f}, \mathrm{EP}\right)$ all over the place. For example, the probability that simulated values are in a ball centered around the actual values of

\footnotetext{
${ }^{2}$ The three consumption states are $\lambda_{1}=1+\mu+\nu, \lambda_{2}=1+\mu-\nu, \lambda_{3}=\xi *(1+\mu)$ and the transition matrix has elements: $\phi_{1,1}=\phi_{2,2}=\phi ; \phi_{1,2}=\phi_{2,1}=1-\phi-\zeta, \phi_{1,3}=\phi_{2,3}=\zeta, \phi_{3,1}=$ $\phi_{3,2}=0.5, \phi_{3,3}=0.0$. Note that the experiment is conceptually different from the previous ones since there are two extra degrees of freedom (the new parameters $\xi$ and $\zeta$ ) and no extra moments to be matched.
} 
$\left(R^{f}, E P\right)$ is now only $72.7 \%$, the probabilities that the model generates values in each of the four quadrants delimited by the actual values of $\left(R^{f}, E P\right)$ are almost identical and the maximum EP consistent with a value of $R^{f}$ below $4 \%$ is 0.747 . In essence, adding a crash state shifts the mode and stretches and tilts the shape of the joint simulated distribution. Roughly speaking, too many configurations for $\left(R^{f}, \mathrm{EP}\right)$ now have equal probability and this weakens the ability of the theory to provide a coherent answer to the question posed.

\subsection{How Much Do Technology Shocks Explain?}

Kydland and Prescott (1982) showed that a one sector growth model driven by technology shocks whose statistical properties have been calibrated to be the same as those of Solow residuals explains about $70 \%$ of the variance of actual US output. This result has spurred much of the subsequent literature which tries to account for business cycle regularities in a model where monetary impulses play no role (the so-called real business cycle literature). Kydland and Prescott's initial estimate has been refined by adding and subtracting features to the basic model (see Hansen (1985)) but the message of their experiment remains: a model where technology shocks are the only source of disturbance explains a large portion of the variability of actual US output.

Recently, Eichenbaum (1991) has questioned this claim because "decisions based solely on the point estimate of $\lambda_{y}$ (the ratio of the variance of simulated and actual cyclical component of output) are whimsical" and suggests that "the model and the data, taken together, are almost completely uninformative about the role of technology shocks in generating fluctuations in US output" (p. 614-615). Using an exactly identified GMM procedure to estimate the free parameters, he finds that the model explains anywhere between $5 \%$ and $200 \%$ of the variance of per-capita US output.

In this section I will repeat Eichenbaum's exercise with three goals in mind. First, I am interested in knowing what is the most likely value from the point of view of the model (i.e. I am interested in locating the mode of the simulated distribution). Second, I want to provide confidence bands for $\lambda_{y}$ which reflect the intrinsic uncertainty present in the model (not in the data, as in Eichenbaum). Third, I wish to verify whether taking normal confidence bands appropriately describes the uncertainty surrounding point estimates of $\lambda_{y}$ and examine which features of the model make deviations from normality more evident.

The model I use is the same as Eichenbaum's and is a simple variation of Hansen's (1985) model which allows for deterministic growth via labor augmenting technological progress. The social planner of this economy maximizes

$$
E_{o} \sum_{t=o}^{\infty} \beta^{t}\left[\log \left(c_{t}\right)+\theta\left(T-h_{t}\right)\right]
$$

subject to:

$$
c_{t}+k_{t+1}-(1-\delta) k_{t} \leq A_{t} K_{t}^{1-\alpha}\left(\gamma^{t} h_{t}\right)^{\alpha}
$$


where $c_{t}$ is per-capita consumption, $T-h_{t}$ is leisure, $T$ the per-capita endowment of time in a quarter, $E_{o}$ is the time 0 conditional expectation operator, $k_{t}$ is the capital stock at time $t$ and $A_{t}$ is an aggregate technology shock with the time series representation $A_{t}=A_{t-1}^{\rho} e^{\epsilon_{t}}$, where $|\rho|<1$ and $\epsilon_{t} \sim \operatorname{iid}\left(\bar{\epsilon}, \sigma^{2}\right)$. A justification for a specification like (11) can be found in Hansen (1985). Since the model is nonlinear and variables grow over time, a closed form stationary solution does not exist. Here I compute an approximate decision rule for the endogenous variables using a loglinear expansion around the steady states after variables have been linearly detrended as in King, Plosser and Rebelo (1988).

There are seven parameters in the model: $\delta$, the depreciation rate of capital, $\beta$, the subjective discount rate, $\theta$, leisure's weight in the utility function, $\alpha$, labour's share in output, $\gamma$, the constant unconditional growth rate of technology, $\rho$ the AR parameter of the shock and $\sigma$ its standard error. Hansen (1985) calibrated these parameters (the values are in the first column of table 2) and found that $\lambda_{y}=$ $\frac{\operatorname{var}\left(y_{t}^{s}\right)}{\operatorname{var}\left(y_{t}\right)} \approx 1$ where $\operatorname{var}\left(y_{t}^{s}\right)$ is the variance of simulated output. Eichenbaum (1991) estimated all parameters but $\beta$ (which is calibrated) using a method of moment procedure (values and standard errors are in the second column of table 2) and found (i) a point estimate of $\lambda_{y}$ of 0.80 , (ii) a large standard error about the point estimate of $\lambda_{y}$ due primarily to the uncertainty surrounding $\rho$ and $\sigma$ and (iii) a strong sensitivity of the point estimate of $\lambda_{y}$ to small perturbations in the parameter vector.

The densities for the parameters I employ are in the third column of table 2. The range for the quarterly discount factor corresponds to the one implied by the annual range used in the previous example and the density is the same. $\delta$ is chosen so that the annual depreciation rate of the capital stock is uniformly distributed between 8 and $12 \%$ per year. The range is selected because in simulation studies $\delta$ is commonly set to 0.025 , which corresponds to a $10 \%$ annual depreciation rate, while estimates of this parameter lie around this value (e.g. McGratten, Rogerson and Wright (1991) have a quarterly value of 0.0310 and a standard error of 0.0046 , while Burnside, Eichenbaum and Rebelo (1992) have a quarterly value of 0.0209 and a standard error of 0.0003 ). The range for $\alpha$ reflects calculations appearing in Christiano (1988) where, depending on how proprietors' income is treated, the share of total output payed to capital varies between 0.25 and 0.43 , and the estimate obtained, among others, in McGratten, Rogerson and Wright (1991). I chose the densities for $\rho$ and $\sigma$ as in Eichenbaum because the econometric evidence on these two parameters is scant and the values used in most simulation studies fall within a one standard error band around the mean of the assumed density (see e.g. Kydland and Prescott (1982) and Hansen (1985)). Finally, $\mathrm{T}$ is fixed at 1369 hours per quarter, the density for $\gamma$ matches the quarterly distribution of unconditional quarterly growth rates of US output for the period 1960-1990 and $\theta$ is endogenously chosen so that the representative household spends between one sixth and one third of its time working in the steady state.

I performed 1000 simulations with time series of length $\mathrm{T}=124$ and I present a smoothed version of the simulated distribution of $\lambda_{y}$ in figure 5 . The distribution is scaled so that with the parameter values used by Eichenbaum (1991) we generate a 
value of $\lambda_{y}=0.80$. As a reference, the value of $\lambda_{y}$ using Hansen's (1985) parameters is 0.84 .

The mode of the distribution is at 0.9046 , the mean at 0.8775 , the median at 0.5949. The dispersion around these measures of location is very large. For example, the standard deviation is 0.7635 and the 90 percent range of the distribution is $[0.2261,2.6018]$. The simulated distribution is far from normal and the left tail of the distribution tends to be very long. Hence the range of estimates of $\lambda_{y}$ is very large, and, as in Eichenbaum, small perturbations in the parameter vector induce large variations in the variance ratio.

Several other features of the simulated distribution are worth mentioning. First, in $67.3 \%$ of the cases the variance of simulated output is smaller than the variance of actual output. Second, in $43.1 \%$ of the simulations the variance of simulated output is within a classical two standard deviation confidence band around the estimate of the variance of actual output. Third, if I choose an evaluation size $v=0.50$ and find the $\hat{\lambda}$ satisfying $\operatorname{Pr}\left(\lambda_{y_{i}} \leq \hat{\lambda}\right)=0.5$, i.e. $\hat{\lambda}$ is the median of the simulated distribution, I find that the median value of the simulated variance of output is outside the $95 \%$ normal confidence range for the variance of actual output.

When I ask which parameter is responsible for the large uncertainty in the estimates of $\lambda_{y}$, I find that it is the location and width of the support for $\rho$ which induce both a large mean value and a wide dispersion of estimates. For example, assuming that the density of $\rho$ has a point mass at 0.94 and maintaining the same densities for the other parameters, I find that location measures of the simulated distribution for $\lambda_{y}$ decrease (the mode is now at 0.792) and the standard deviation of the simulated distribution for the variance of output drops to 0.529. Similar conclusions are obtained by shifting the range of $\rho$ toward 0.90 or by cutting the range of possible $\rho$ in half without changing the mean value. Hence, as in Eichenbaum, I find that it is the intrinsic uncertainty in the process characterizing the exogenous forces rather than the exact parameterization of the model that is responsible for the large spread in the distribution of outcomes. In addition, I also find that normal confidence bands do not appropriately characterize the uncertainty surrounding the outcomes of the model.

\section{Conclusions}

This paper describes a Monte Carlo procedure to formally evaluate the properties of calibrated general equilibrium models. The procedure is designed to make the choice of parameters and the evaluation of the properties of the model more statistically sound. The approach realistically accounts for the uncertainty faced by a simulator in choosing the parameters of the model by assuming that they are drawn from the frequency distribution of existing estimates. The methodology allows for global sensitivity analysis within the range of existing estimates and evaluates the discrepancy of the model from the data by attaching probabilities to events a simulator 
is interested in characterizing. The approach is easy to implement, computationally simple and includes existing calibration, estimation by simulation and GMM techniques as special cases. The usefulness of the approach as a tool to evaluate the performance of theoretical models is gauged using two applications which have received substantial attention in the literature: the equity premium puzzle and the ability of a real business cycle model to reproduce the variance of actual US output. 


\section{References}

[1] Altug, S. (1989), "Time to Build and Aggregate Fluctuations: Some New Evidence", International Economic Review, 30, 889-920.

[2] Backus, D., Gregory, A. and S. Zin (1989), "Risk Premiums in the Terms Structure: Evidence from Artificial Economies", Journal of Monetary Economics, 24, 371-399.

[3] Baxter, M. (1991), "Approximating Suboptimal Dynamic Equilibria: An Euler Equation Approach", Journal of Monetary Economics, 27, 173-200.

[4] Benninga, S. and A. Protopapadakis (1990), "Leverage, Time Preference, and the Equity Premium Puzzle", Journal of Monetary Economics, 25, 49-58.

[5] Burnside, C., Eichenbaum, M., and Rebelo, S. (1992), "Labor Hoarding and the Business Cycle", NBER working paper 3556, forthcoming Journal of Political Economy.

[6] Canova, F. and Marrinan, J. (1991), "Profits, Risk and Uncertainty in Foreign Exchange Markets", European University Institute, working paper ECO 92/73.

[7] Canova, F., Finn, M. and Pagan, A. (1992), "Evaluating a Real Business Cycle Model", forthcoming, in C. Hargreaves, Nonstationary Time Series Analyses and Cointegration, Oxford University Press.

[8] Christiano, L. (1988), "Why Does Inventory Fluctuate so Much?", Journal of Monetary Economics, 21, 247-280.

[9] Christiano, L. (1990), "Solving the Stochastic Growth Model by Linear Quadratic Approximation and by Value Function Iteration", Journal of Business and Economic Statistics, 8, 23-26.

[10] Coleman, W. (1989), "An Algorithm to Solve Dynamic Models", Board of Governors of the Federal Reserve System, International Finance Division, Discussion Paper no. 351.

[11] Dotsey, M. and Mao, C.S. (1991), "How Well do Linear Approximation Methods Work? Results for Suboptimal Dynamic Equilibria", Journal of Monetary Economics, 29(1), 25-58.

[12] Dunn, D. and Singleton, K. (1986), "Modelling the Term Structure of Interest Rates under Nonseparable Utility and Durability of Goods", Journal of Financial Economics, 17, 27-55.

[13] Eichenbaum, M. (1991), "Real Business Cycle Theory: Wisdom or Whimsy", Journal of Economic Dynamic and Control, 15, 607-621. 
[14] Fair, R. (1991), "Estimating Event Probabilities from Macroeconomic Models using Stochastic Simulations", Yale University, manuscript.

[15] Friedman, M. (1959), Essays in Positive Economics, New York, Aldine Press.

[16] Frisch, R., "Propagation Problems and Impulse Problems in Dynamics Economies", in Economic Essays in Honor of Gustav Cassel, London.

[17] Geweke, J. (1989), "Bayesian Inference in Econometric Models Using Monte Carlo Integration", Econometrica, 57, 1317-1339.

[18] Gelfand A. and Smith A. (1990), "Sampling Based Approaches to Calculating Marginal Densities", Journal of the American Statistical Association, 85, 398409.

[19] Gregory, A. and Smith, G. (1989), "Calibration as Estimation", Econometric Reviews, 9(1), 57-89.

[20] Gregory, A. and Smith, G. (1991a), "Calibration as Testing: Inference in Simulated Macro Models", Journal of Business and Economic Statistics, 9(3), 293303.

[21] Haavelmo, (1944), "The Probability Approach in Econometrics", Econometrica, 12, Supplement.

[22] Hansen, G. (1985), "Indivisible Labor and the Business Cycle", Journal of Monetary Economics, 16, 309-328.

[23] Hansen, L. and Sargent, T. (1979), "Formulating and Estimating Dynamic Linear Rational Expectations Models", Journal of Economic Dynamic and Control, $2,7-46$.

[24] Hansen, L. and Singleton, K. (1983), "Stochastic Consumption, Risk Aversion and Temporal Behavior of Asset Returns", Journal of Political Economy, 91, 249-265.

[25] Harrison, G. and Vinod, H. D. (1989), "Sensitivity Analysis of Applied General Equilibrium Models: Completely Randomized Factorial Sampling Designs", University of New Mexico, manuscript.

[26] Harsaee, E. (1987), "Empirical Bayes Methods and the Kalman Filter, University of Aarhus, memo 87-9.

[27] Journal of Business and Economic Statistics, January 1990.

[28] Judd, K. (1989), "Minimum Weighted Residual Methods in Dynamic Economic Models", Hoover Institution, manuscript.

[29] Kandel, S. and Stambaugh, R. (1990), "Expectations and Volatility of Consumption and Asset Returns", Review of Financial Studies, 3, 207-232. 
[30] King, R., Plosser, C. and Rebelo S. (1988), "Production, Growth and Business Cycles: I and II", Journal of Monetary Economics, 21, 195-232 and 309-342.

[31] Kocherlakota, N. (1990), "On the Discount Factor in Growth Economies", Journal of Monetary Economics, 25, 45-48

[32] Kydland, F. (1992), "On the Econometrics of World Business Cycles", European Economic Review, 36, 476-482.

[33] Kydland, F. and Prescott, E. (1982), "Time To Build and Aggregate Fluctuations", Econometrica, 50, 1345-1370.

[34] Kydland, F. and Prescott, E. (1991), "The Econometrics of the General Equilibrium Approach to Business Cycles", The Scandinavian Journal of Economics, 93(2),161-178.

[35] Kwan, Y.K. (1990), "Bayesian Calibration with an Application to a Non-linear Rational Expectation Two Country Model", mimeo, University of Chicago Business School.

[36] Lee, B.S. and Ingram, B. (1991), "Simulation Estimators of Time Series Models", Journal of Econometrics, 47(2/3), 197-206.

[37] Merha, R. and Prescott, E. (1985), "The Equity Premium: A Puzzle", Journal of Monetary Economics, 15,145-162.

[38] Merha, R. and Prescott, E. (1988), "The Equity Risk Premium: A Solution?", Journal of Monetary Economics, 22, 133-136.

[39] McGratten, E. , Rogerson, R. and Wright, R. (1991), "Estimating the Stochastic Growth Model with Household Production", Federal Reserve Bank of Minneapolis, manuscript.

[40] Niederreiter, H. (1988), "Quasi Monte Carlo Methods for Multidimensional Numerical Integration", International Series of Numerical Mathematics, 85, 157-171.

[41] Novales, A. (1990), "Solving Nonlinear Rational Expectations Models: A Stochastic Equilibrium Model of Interest Rates", Econometrica, 58, 93-111.

[42] Pagan, A. and Ullah, A. (1991), "Nonparametric Estimation", University of Rochester, manuscript.

[43] Phillips, P.C.B. (1991), "To Criticize the Critics: An Objective Bayesian Analysis of Stochastic Trends", Journal of Applied Econometrics, 6(4), 333-354.

[44] Prescott, E. (1991), "Real Business Cycle Theories: What Have we Learned?", Federal Reserve of Minneapolis, working paper 486.

[45] Reitz, T. (1988), "The Equity Risk Premium: A Solution", Journal of Monetary Economics, 22, 117-132. 
[46] Shoven, J. and Whalley, J. (1984), "Applied General Equilibrium Models of Taxation and International Trade: An Introduction and Survey", Journal of Economic Literature, 22, 1007-1051.

[47] Sims, C. (1984), "Solving Nonlinear Stochastic Equilibrium Models Backward", University of Minnesota, manuscript.

[48] Smith, T. (1992), "Estimating Nonlinear Time Series Models using Simulated VAR: Two Approaches", Queen's University, manuscript.

[49] Tanner, M. and Wong, W. (1987), "The Calculation of Posterior Distributions by data Augmentation", Journal of the American Statistical Association, 87, $528-550$.

[50] Tauchen, G. and Hussey, R. (1991), "Quadrature Based Methods for obtaining Approximate Solutions to Integral Equations of Nonlinear Asset Pricing Models", Econometrica, 59, 371-397.

[51] Watson, M. (1990), "Measures of Fit for Calibrated Models", forthcoming, Journal of Political Economy.

[52] Weil, P. (1990), "The Equity Premium Puzzle and the Risk Free Puzzle", Journal of Monetary Economics, 24, 401-421. 
Table 1: Equity Premium Puzzle

A: Parameter Values

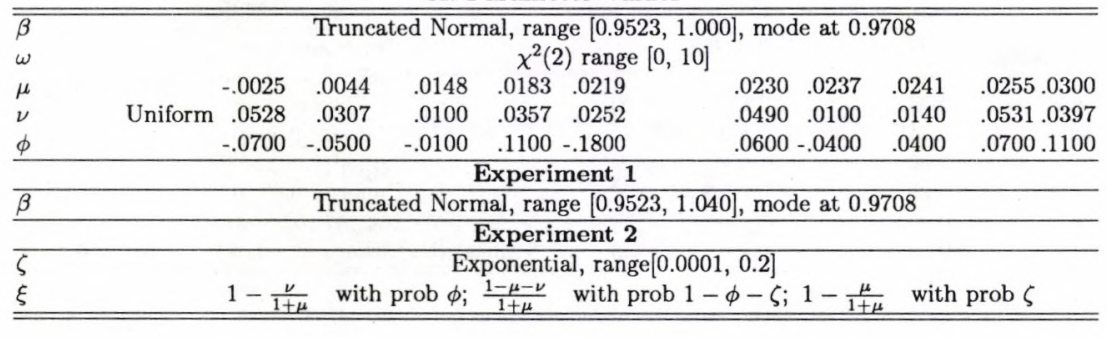

B: Statistics of the Simulated Distribution

\begin{tabular}{|c|c|c|c|c|c|c|c|c|c|c|}
\hline & \multicolumn{2}{|c|}{ M-P Case } & \multirow{2}{*}{$\begin{array}{r}\text { Basic } \\
\text { EP }\end{array}$} & \multirow{2}{*}{$\begin{array}{r}\text { Case } 1 \\
\mathrm{R} \\
\end{array}$} & \multicolumn{2}{|c|}{ Basic Case 2} & \multirow{2}{*}{$\begin{array}{c}\text { Experiment } \\
\text { EP }\end{array}$} & \multicolumn{3}{|c|}{ Experiment 2} \\
\hline & EP & $\mathrm{R}$ & & & EP & $\mathrm{R}$ & & $\mathrm{R}$ & EP & $\mathrm{R}$ \\
\hline Mean & 0.0094 & 0.0913 & 0.0035 & 0.0702 & 0.0015 & 0.0670 & 0.032 & -0.061 & 0.1087 & -0.1519 \\
\hline s.d. & 0.0067 & 0.0379 & 0.0073 & 0.0470 & 0.0032 & 0.0433 & $0.0066 c$ & 0.0419 & 0.1808 & 0.3327 \\
\hline skewness & 0.35 & -0.15 & 2.66 & 1.15 & 3.32 & 1.18 & 2.68 & 1.14 & 1.58 & -1.57 \\
\hline kurtosis & -1.08 & -0.86 & 6.67 & 0.42 & 12.95 & 0.42 & 6.83 & 0.39 & 1.03 & 0.86 \\
\hline maximum & 0.022 & 0.167 & 0.034 & 0.215 & 0.022 & 0.203 & 0.031 & 0.061 & 0.747 & 0.224 \\
\hline $5 \%$ & 0.0005 & 0.0280 & 0.00001 & 0.023 & 0.00001 & 0.023 & 0.00001 & -0.107 & 0.00002 & -0.938 \\
\hline median & 0.0084 & 0.094 & 0.0002 & 0.051 & 0.0001 & 0.0499 & 0.0001 & -0.008 & 0.0098 & 0.022 \\
\hline $95 \%$ & 0.021 & 0.150 & 0.022 & 0.170 & 0.0079 & 0.159 & 0.019 & 0.020 & 0.511 & 0.068 \\
\hline mode & 0.0094 & 0.110 & 0.0008 & 0.052 & 0.0001 & 0.0478 & 0.0001 & -0.074 & 0.007 & -0.018 \\
\hline Pr1 & 0.736 & & 0.817 & & 0.803 & & 0.855 & & 0.727 & \\
\hline \multirow[t]{2}{*}{$\operatorname{Pr} 2$} & 0.994 & 0.00 & 0.994 & 0.00 & 1.000 & 0.00 & 0.927 & 0.00 & 0.577 & 0.295 \\
\hline & 0.006 & 0.00 & 0.001 & 0.00 & 0.00 & 0.00 & 0.073 & 0.00 & 0.126 & 0.002 \\
\hline Pr 3 & 0.99 & & 0.99 & & 0.99 & & 0.95 & & 0.62 & \\
\hline
\end{tabular}

Note: $\operatorname{Pr} 1$ refers to the frequency of simulations for which the pair $\left(R^{f}, \mathrm{EP}\right)$ is in a classical $95 \%$ region around the actual values. Pr2 reports the probability that the model generates values in each of the four quadrants delimited by the actual pair of $\left(R^{f}, \mathrm{EP}\right)$. Pr3 reports the percentile of the simulated distribution where the actual $\left(R^{f}, \mathrm{EP}\right)$ pair lies. 
Table 2: Indivisible Labor Model

A: Parameter Values

\begin{tabular}{lllc}
\hline \hline & Hansen (1985) & Eichenbaum (1991) & Canova (1992) \\
\hline \hline$\beta$ & 0.99 & 0.9926 & Truncated Normal, \\
$\theta$ & & & range [0.9855; 1.002$],$ mode 0.9926 \\
$\alpha$ & 2.60 & $3.6779(0.0003)$ & Endogenous \\
$\gamma$ & 0.64 & $0.6553(0.0570)$ & Uniform [0.50; 0.75] \\
$\delta$ & 1.00 & $1.0041(0.0003)$ & Normal $(1.002,0.001)$ \\
$\rho$ & 0.25 & $0.0209(0.0003)$ & Normal $(0.02 ; 0.03]$ \\
$\sigma$ & 0.95 & $0.9772(0.0289)$ & Truncated $\chi^{2}$, range $[0 ; 0.0091]$, mean 0.0073 \\
\hline \hline
\end{tabular}

B: Statistics of the Simulated Distribution

\begin{tabular}{ll}
\hline \hline Mean & 0.8775 \\
s.d. & 0.7635 \\
skewness & 1.9802 \\
kurtosis & 4.4083 \\
minimum & 0.1566 \\
maximum & 7.2355 \\
$5 \%$ & 0.2261 \\
median & 0.5949 \\
$95 \%$ & 2.6018 \\
mode & 0.9046 \\
Pr1 & 0.427 \\
Pr2 & 0.673 \\
\hline \hline
\end{tabular}

Note: Estimated standard errors are in parenthesis. Pr1 refers to the frequency of simulations for which the variance of simulated output is in a classical $95 \%$ region around the actual value of the variance of detrended output. Pr2 reports the percentile of the simulated distribution where the point estimate of the actual variance of output lies. 

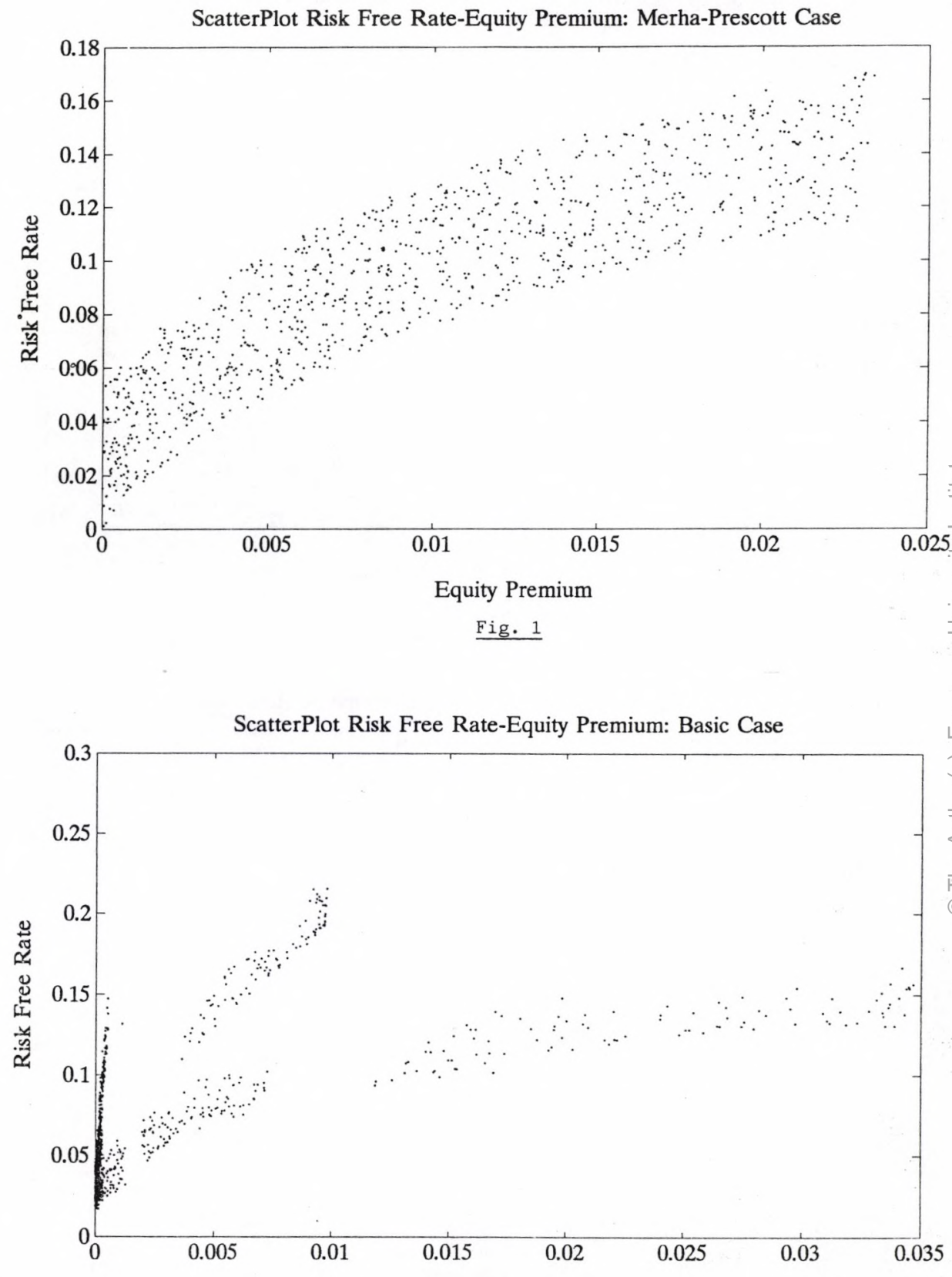

Equity Premium

Fig. ? 
ScatterPlot Risk Free Rate-Equity Premium: Beta $>1$ Case

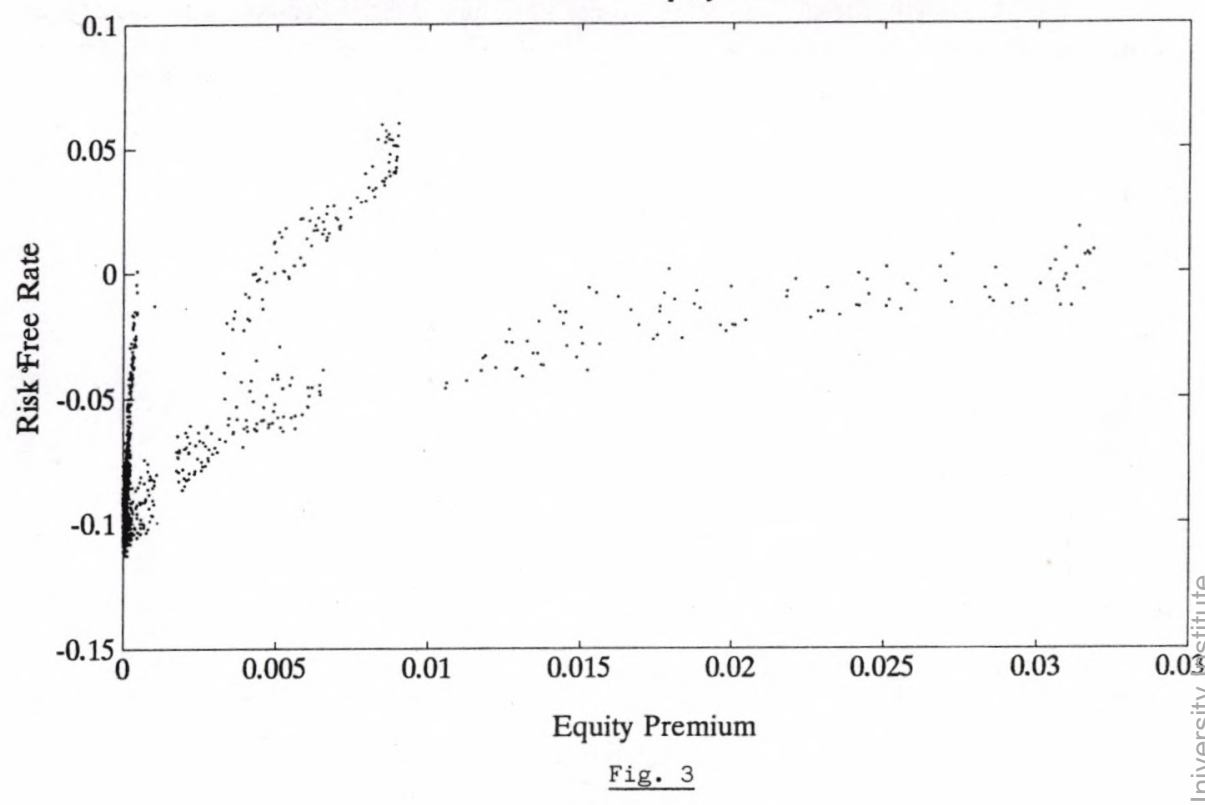

ScatterPlot Risk Free Rate-Equity Premium: Reitz Case

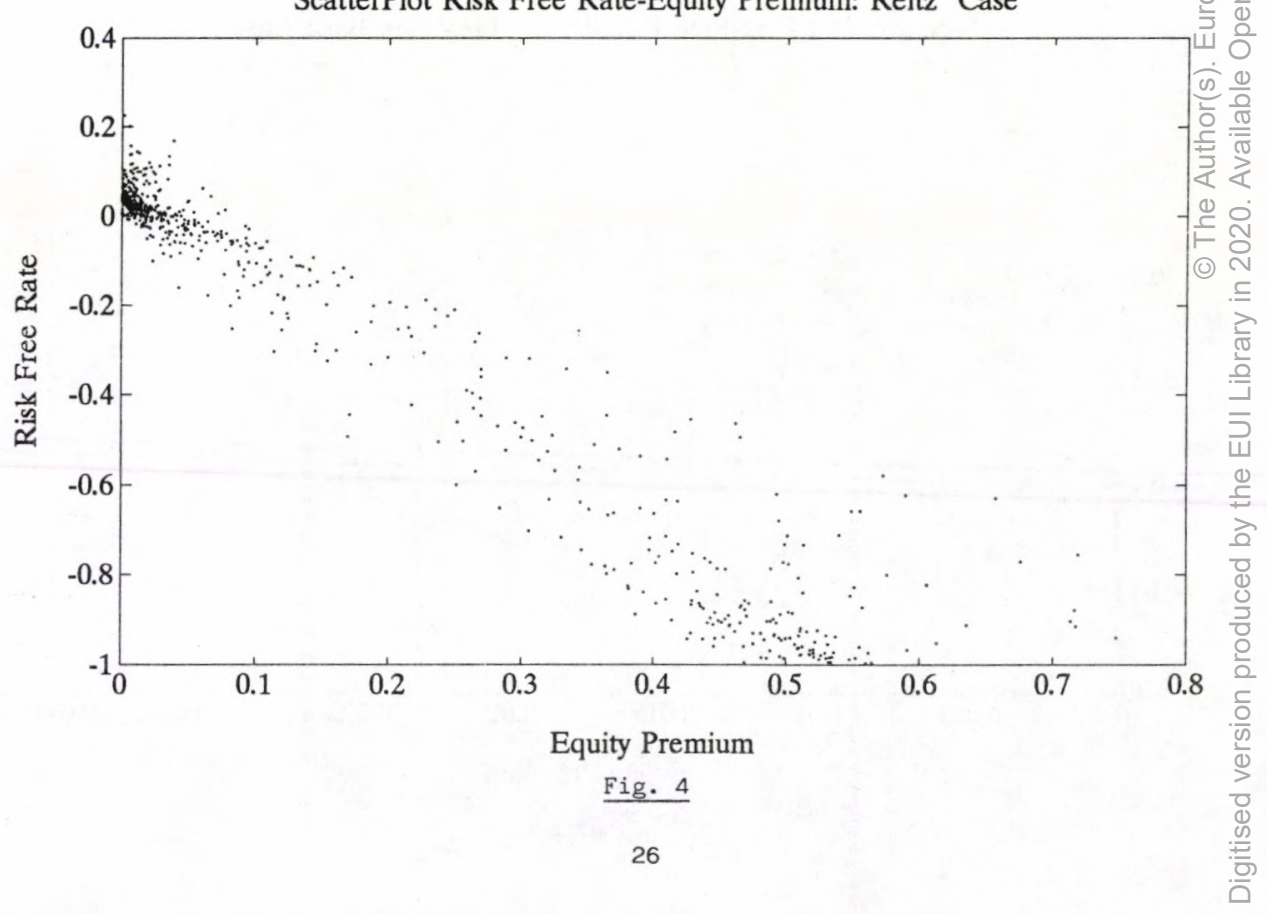


Density of variance ratio: HP filtered data

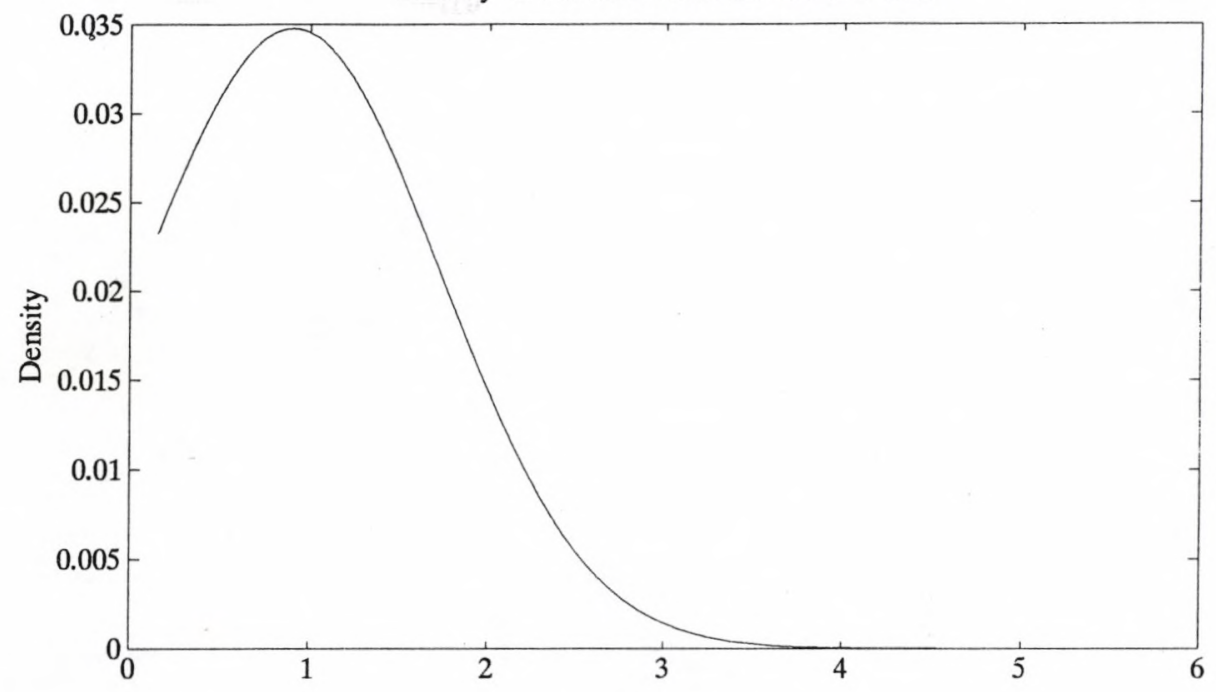

Value of variance ratio

Fig. 5 


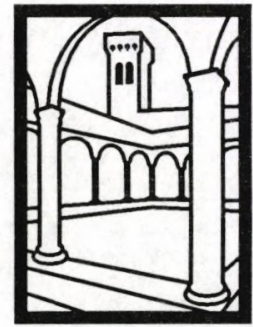

EUI

WORKING

PAPERS

EUI Working Papers are published and distributed by the European University Institute, Florence

Copies can be obtained free of charge

- depending on the availability of stocks - from:

The Publications Officer

European University Institute

Badia Fiesolana

I-50016 San Domenico di Fiesole (FI)

Italy 


\section{Publications of the European University Institute}

To The Publications Officer

European University Institute

Badia Fiesolana

I-50016 San Domenico di Fiesole (FI) - Italy

Telefax No: $+39 / 55 / 573728$

From Name

Address.

$\square$ Please send me a complete list of EUI Working Papers

$\square$ Please send me a complete list of EUI book publications

$\square$ Please send me the EUI brochure Academic Year 1994/95

$\square$ Please send me the EUI Research Review

Please send me the following EUI Working Paper(s):

No, Author

Title:

No, Author

Title:

No, Author

Title:

No, Author

Title:

Date

Signature 
European University Institute

\section{LEAVE IN BOOK}

The loan period for this item expires on:

$3 / 10 / 94$

告 


\section{Working Papers of the Department of Economics Published since 1990}

ECO No. 90/1

Tamer BASAR and Mark SALMON

Credibility and the Value of Information

Transmission in a Model of Monetary

Policy and Inflation

ECO No. 90/2

Horst UNGERER

The EMS - The First Ten Years

Policies - Developments - Evolution

ECO No. 90/3

Peter J. HAMMOND

Interpersonal Comparisons of Utility:

Why and how they are and should be

made

ECO No. 90/4

Peter J. HAMMOND

A Revelation Principle for (Boundedly)

Bayesian Rationalizable Strategies

ECO No. $90 / 5$

Peter J. HAMMOND

Independence of Irrelevant Interpersonal Comparisons

ECO No. 90/6

Hal R. VARIAN

A Solution to the Problem of

Externalities and Public Goods when

Agents are Well-Informed

ECO No. 90/7

Hal R. VARIAN

Sequential Provision of Public Goods

ECO No. 90/8

T. BRIANZA, L. PHLIPS and J.F.

RICHARD

Futures Markets, Speculation and

Monopoly Pricing

ECO No. 90/9

Anthony B. ATKINSON/ John

MICKLEWRIGHT

Unemployment Compensation and

Labour Market Transition: A Critical

Review

ECO No. 90/10

Peter J. HAMMOND

The Role of Information in Economics
ECO No. 90/11

Nicos M. CHRISTODOULAKIS

Debt Dynamics in a Small Open

Economy

ECO No. 90/12

Stephen C. SMITH

On the Economic Rationale for

Codetermination Law

ECO No. 90/13

Elettra AGLIARDI

Learning by Doing and Market Structures

ECO No. 90/14

Peter J. HAMMOND

Intertemporal Objectives

ECO No. 90/15

Andrew EVANS/Stephen MARTIN

Socially Acceptable Distortion of

Competition: EC Policy on State Aid

ECO No. 90/16

Stephen MARTIN

Fringe Size and Cartel Stability

ECO No. 90/17

John MICKLEWRIGHT

Why Do Less Than a Quarter of the

Unemployed in Britain Receive

Unemployment Insurance?

ECO No. 90/18

Mrudula A. PATEL

Optimal Life Cycle Saving With

Borrowing Constraints:

A Graphical Solution

ECO No. 90/19

Peter J. HAMMOND

Money Metric Measures of Individual and Social Welfare Allowing for

Environmental Externalities

ECO No. 90/20

Louis PHLIPS/

Ronald M. HARSTAD

Oligopolistic Manipulation of Spot

Markets and the Timing of Futures

Market Speculation 
ECO No. 90/21

Christian DUSTMANN

Earnings Adjustment of Temporary

Migrants

ECO No. 90/22

John MICKLEWRIGHT

The Reform of Unemployment

Compensation:

Choices for East and West

ECO No. $90 / 23$

Joerg MAYER

U. S. Dollar and Deutschmark as

Reserve Assets

ECO No. 90/24

Sheila MARNIE

Labour Market Reform in the USSR:

Fact or Fiction?

ECO No. 90/25

Peter JENSEN/

Niels WESTERGÅRD-NIELSEN

Temporary Layoffs and the Duration of

Unemployment: An Empirical Analysis

ECO No. 90/26

Stephan L. KALB

Market-Led Approaches to European

Monetary Union in the Light of a Legal

Restrictions Theory of Money

ECO No. 90/27

Robert J. WALDMANN

Implausible Results or Implausible Data?

Anomalies in the Construction of Value

Added Data and Implications for Esti-

mates of Price-Cost Markups

ECO No. 90/28

Stephen MARTIN

Periodic Model Changes in Oligopoly

ECO No. 90/29

Nicos CHRISTODOULAKIS/

Martin WEALE

Imperfect Competition in an Open

Economy
洸潘

ECO No. 91/30

Steve ALPERN/Dennis J. SNOWER

Unemployment Through 'Learning From

Experience'

ECO No. 91/31

David M. PRESCOTT/Thanasis

STENGOS

Testing for Forecastible Nonlinear

Dependence in Weekly Gold Rates of

Return

ECO No. $91 / 32$

Peter J. HAMMOND

Harsanyi's Utilitarian Theorem:

A Simpler Proof and Some Ethical

Connotations

ECO No. 91/33

Anthony B. ATKINSON/

John MICKLEWRIGHT

Economic Transformation in Eastern

Europe and the Distribution of Income*

ECO No. 91/34

Svend ALBAEK

On Nash and Stackelberg Equilibria

when Costs are Private Information

ECO No. 91/35

Stephen MARTIN

Private and Social Incentives

to Form R \& D Joint Ventures

ECO No. 91/36

Louis PHLIPS

Manipulation of Crude Oil Futures

ECO No. 91/37

Xavier CALSAMIGLIA/Alan KIRMAN

A Unique Informationally Efficient and

Decentralized Mechanism With Fair

Outcomes

ECO No. 91/38

George S. ALOGOSKOUFIS/

Thanasis STENGOS

Testing for Nonlinear Dynamics in

Historical Unemployment Series

ECO No. 91/39

Peter J. HAMMOND

The Moral Status of Profits and Other

Rewards:

A Perspective From Modern Welfare

Economics 
ECO No. 91/40

Vincent BROUSSEAU/Alan KIRMAN

The Dynamics of Learning in Mis-

Specified Models

ECO No. 91/41

Robert James WALDMANN

Assessing the Relative Sizes of Industryand Nation Specific Shocks to Output

ECO No. 91/42

Thorsten HENS/Alan KIRMAN/Louis

PHLIPS

Exchange Rates and Oligopoly

ECO No. 91/43

Peter J. HAMMOND

Consequentialist Decision Theory and

Utilitarian Ethics

ECO No. 91/44

Stephen MARTIN

Endogenous Firm Efficiency in a Cournot

Principal-Agent Model

\section{ECO No. 91/45}

Svend ALBAEK

Upstream or Downstream Information Sharing?

ECO No. 91/46

Thomas H. McCURDY/

Thanasis STENGOS

A Comparison of Risk-Premium

Forecasts Implied by Parametric Versus

Nonparametric Conditional Mean

Estimators

ECO No. 91/47

Christian DUSTMANN

Temporary Migration and the Investment into Human Capital

ECO No. 91/48

Jean-Daniel GUIGOU

Should Bankruptcy Proceedings be

Initiated by a Mixed

Creditor/Shareholder?

ECO No. 91/49

Nick VRIEND

Market-Making and Decentralized Trade

ECO No. 91/50

Jeffrey L. COLES/Peter J. HAMMOND

Walrasian Equilibrium without Survival:

Existence, Efficiency, and Remedial

Policy
ECO No. 91/51

Frank CRITCHLEY/Paul MARRIOTT/

Mark SALMON

Preferred Point Geometry and Statistical Manifolds

ECO No. 91/52

Costanza TORRICELLI

The Influence of Futures on Spot Price

Volatility in a Model for a Storable

Commodity

ECO No. 91/53

Frank CRITCHLEY/Paul MARRIOTT/

Mark SALMON

Preferred Point Geometry and the Local Differential Geometry of the Kullback-

Leibler Divergence

ECO No. 91/54

Peter MØLLGAARD/

Louis PHLIPS

Oil Futures and Strategic

Stocks at Sea

ECO No. 91/55

Christian DUSTMANN/

John MICKLEWRIGHT

Benefits, Incentives and Uncertainty

ECO No. 91/56

John MICKLEWRIGHT/

Gianna GIANNELLI

Why do Women Married to Unemployed Men have Low Participation Rates?

ECO No. 91/57

John MICKLEWRIGHT

Income Support for the Unemployed in Hungary

ECO No. 91/58

Fabio CANOVA

Detrending and Business Cycle Facts

ECO No. 91/59

Fabio CANOVAV

Jane MARRINAN

Reconciling the Term Structure of

Interest Rates with the Consumption

Based ICAP Model

ECO No. 91/60

John FINGLETON

Inventory Holdings by a Monopolist

Middleman 
洸洸

ECO No. 92/61

Sara CONNOLLY/John

MICKLEWRIGHT/Stephen NICKELL

The Occupational Success of Young Men

Who Left School at Sixteen

ECO No. 92/62

Pier Luigi SACCO

Noise Traders Permanence in Stock

Markets: A Tâtonnement Approach.

I: Informational Dynamics for the Two-

Dimensional Case

ECO No. 92/63

Robert J. WALDMANN

Asymmetric Oligopolies

ECO No. 92/64

Robert J. WALDMANN/Stephen

C. SMITH

A Partial Solution to the Financial Risk and Perverse Response Problems of Labour-Managed Firms: Industry-

Average Performance Bonds

ECO No. 92/65

Agustín MARAVALL/Víctor GÓMEZ

Signal Extraction in ARIMA Time Series Program SEATS

ECO No. 92/66

Luigi BRIGHI

A Note on the Demand Theory of the

Weak Axioms

ECO No. 92/67

Nikolaos GEORGANTZIS

The Effect of Mergers on Potential

Competition under Economies or

Diseconomies of Joint Production

ECO No. 92/68

Robert J. WALDMANN/

J. Bradford DE LONG

Interpreting Procyclical Productivity:

Evidence from a Cross-Nation Cross-

Industry Panel

ECO No. 92/69

Christian DUSTMANN/John

MICKLEWRIGHT

Means-Tested Unemployment Benefit and Family Labour Supply: A Dynamic Analysis
ECO No. 92/70

Fabio CANOVA/Bruce E. HANSEN

Are Seasonal Patterns Constant Over

Time? A Test for Seasonal Stability

ECO No. 92/71

Alessandra PELLONI

Long-Run Consequences of Finite

Exchange Rate Bubbles

ECO No. 92/72

Jane MARRINAN

The Effects of Government Spending on

Saving and Investment in an Open

Economy

ECO No. 92/73

Fabio CANOVA and Jane MARRINAN

Profits, Risk and Uncertainty in Foreign

Exchange Markets

ECO No. 92/74

Louis PHLIPS

Basing Point Pricing, Competition and

Market Integration

ECO No. 92/75

Stephen MARTIN

Economic Efficiency and Concentration:

Are Mergers a Fitting Response?

ECO No. 92/76

Luisa ZANCHI

The Inter-Industry Wage Structure:

Empirical Evidence for Germany and a

Comparison With the U.S. and Sweden

ECO NO. 92/77

Agustín MARAVALL

Stochastic Linear Trends: Models and

Estimators

ECO No. 92/78

Fabio CANOVA

Three Tests for the Existence of Cycles in Time Series

ECO No. 92/79

Peter J. HAMMOND/Jaime SEMPERE Limits to the Potential Gains from Market Integration and Other Supply-Side Policies 
ECO No. 92/80

Víctor GÓMEZ and Agustín

MARAVALL

Estimation, Prediction and Interpolation for Nonstationary Series with the

Kalman Filter

ECO No. 92/81

Víctor GÓMEZ and Agustín

MARAVALL

Time Series Regression with ARIMA

Noise and Missing Observations

Program TRAM

ECO No. 92/82

J. Bradford DE LONG/ Marco BECHT

"Excess Volatility" and the German

Stock Market, 1876-1990

ECO No. $92 / 83$

Alan KIRMAN/Louis PHLIPS

Exchange Rate Pass-Through and Market

Structure

ECO No. 92/84

Christian DUSTMANN

Migration, Savings and Uncertainty

ECO No. 92/85

J. Bradford DE LONG

Productivity Growth and Machinery

Investment: A Long-Run Look, 18701980

ECO NO. 92/86

Robert B. BARSKY and J. Bradford DE LONG

Why Does the Stock Market Fluctuate?

ECO No. 92/87

Anthony B. ATKINSON/John

MICKLEWRIGHT

The Distribution of Income in Eastern

Europe

\section{ECO No.92/88}

Agustín MARAVALLAlexandre

MATHIS

Encompassing Unvariate Models in

Multivariate Time Series: A Case Study

ECO No. $92 / 89$

Peter J. HAMMOND

Aspects of Rationalizable Behaviour
ECO 92/90

Alan P. KIRMAN/Robert

J. WALDMANN

I Quit

ECO No. 92/91

Tilman EHRBECK

Rejecting Rational Expectations in Panel

Data: Some New Evidence

ECO No. 92/92

Djordje Suvakovic OLGIN

Simulating Codetermination in a

Cooperative Economy

ECO No. 92/93

Djordje Suvakovic OLGIN

On Rational Wage Maximisers

ECO No. 92/94

Christian DUSTMANN

Do We Stay or Not? Return Intentions of Temporary Migrants

ECO No. 92/95

Djordje Suvakovic OLGIN

A Case for a Well-Defined Negative

Marxian Exploitation

ECO No. 92/96

Sarah J. JARVIS/John

MICKLEWRIGHT

The Targeting of Family Allowance in

Hungary

ECO No. 92/97

Agustín MARAVALL/Daniel PEÑA

Missing Observations and Additive

Outliers in Time Series Models

ECO No. 92/98

Marco BECHT

Theory and Estimation of Individual and

Social Welfare Measures: A Critical

Survey

ECO No. 92/99

Louis PHLIPS and Ireneo Miguel

MORAS

The AKZO Decision: A Case of

Predatory Pricing?

ECO No. 92/100

Stephen MARTIN

Oligopoly Limit Pricing With Firm-

Specific Cost Uncertainty 
ECO No. 92/101

Fabio CANOVA/Eric GHYSELS

Changes in Seasonal Patterns: Are They Cyclical?

ECO No. 92/102

Fabio CANOVA

Price Smoothing Policies: A Welfare

Analysis

\section{米洸洸}

ECO No. 93/1

Carlo GRILLENZONI

Forecasting Unstable and Non-Stationary

Time Series

ECO No. 93/2

Carlo GRILLENZONI

Multilinear Models for Nonlinear Time

Series

ECO No. 93/3

Ronald M. HARSTAD/Louis PHLIPS

Futures Market Contracting When You

Don't Know Who the Optimists Are

ECO No. 93/4

Alan KIRMAN/Louis PHLIPS

Empirical Studies of Product Markets

ECO No. 93/5

Grayham E. MIZON

Empirical Analysis of Time Series:

Illustrations with Simulated Data

ECO No. 93/6

Tilman EHRBECK

Optimally Combining Individual

Forecasts From Panel Data

ECO NO. 93/7

Víctor GÓMEZ/Agustín MARAVALL Initializing the Kalman Filter with Incompletely Specified Initial Conditions

ECO No. 93/8

Frederic PALOMINO

Informed Speculation: Small Markets

Against Large Markets

ECO NO. 93/9

Stephen MARTIN

Beyond Prices Versus Quantities
ECO No. 93/10

José María LABEAGA/Angel LÓPEZ

A Flexible Demand System and VAT

Simulations from Spanish Microdata

ECO No. 93/11

Maozu LU/Grayham E. MIZON

The Encompassing Principle and

Specification Tests

ECO No. 93/12

Louis PHLIPS/Peter MØLLGAARD

Oil Stocks as a Squeeze Preventing

Mechanism: Is Self-Regulation Possible?

ECO No. 93/13

Pieter HASEKAMP

Disinflation Policy and Credibility: The

Role of Conventions

ECO No. 93/14

Louis PHLIPS

Price Leadership and Conscious

Parallelism: A Survey

ECO No. 93/15

Agustín MARAVALL

Short-Term Analysis of Macroeconomic

Time Series

ECO No. 93/16

Philip Hans FRANSES/Niels

HALDRUP

The Effects of Additive Outliers on Tests

for Unit Roots and Cointegration

ECO No. 93/17

Fabio CANOVA/Jane MARRINAN

Predicting Excess Returns in Financial Markets

ECO No. 93/18

Iñigo HERGUERA

Exchange Rate Fluctuations, Market

Structure and the Pass-through

Relationship

ECO No. 93/19

Agustín MARAVALL

Use and Misuse of Unobserved

Components in Economic Forecasting 
ECO No. 93/20

Torben HOLVAD/Jens Leth

HOUGAARD

Measuring Technical Input Efficiency for Similar Production Units:

A Survey of the Non-Parametric

Approach

ECO No. 93/21

Stephen MARTIN/Louis PHLIPS

Product Differentiation, Market Structure and Exchange Rate Passthrough

ECO No 93/22

F. CANOVA/M. FINN/A. R. PAGAN

Evaluating a Real Business Cycle Model

ECO No 93/23

Fabio CANOVA

Statistical Inference in Calibrated Models 


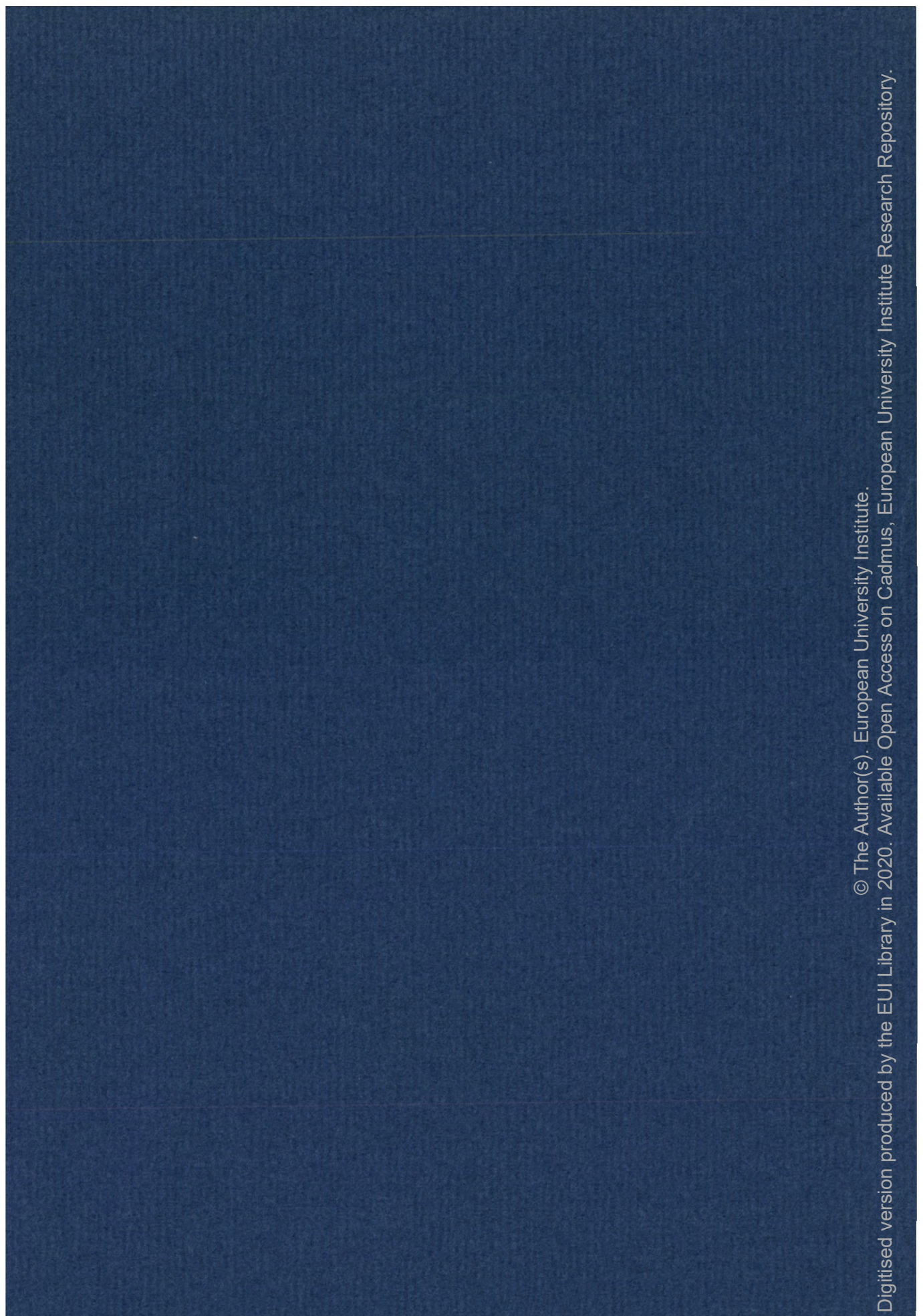




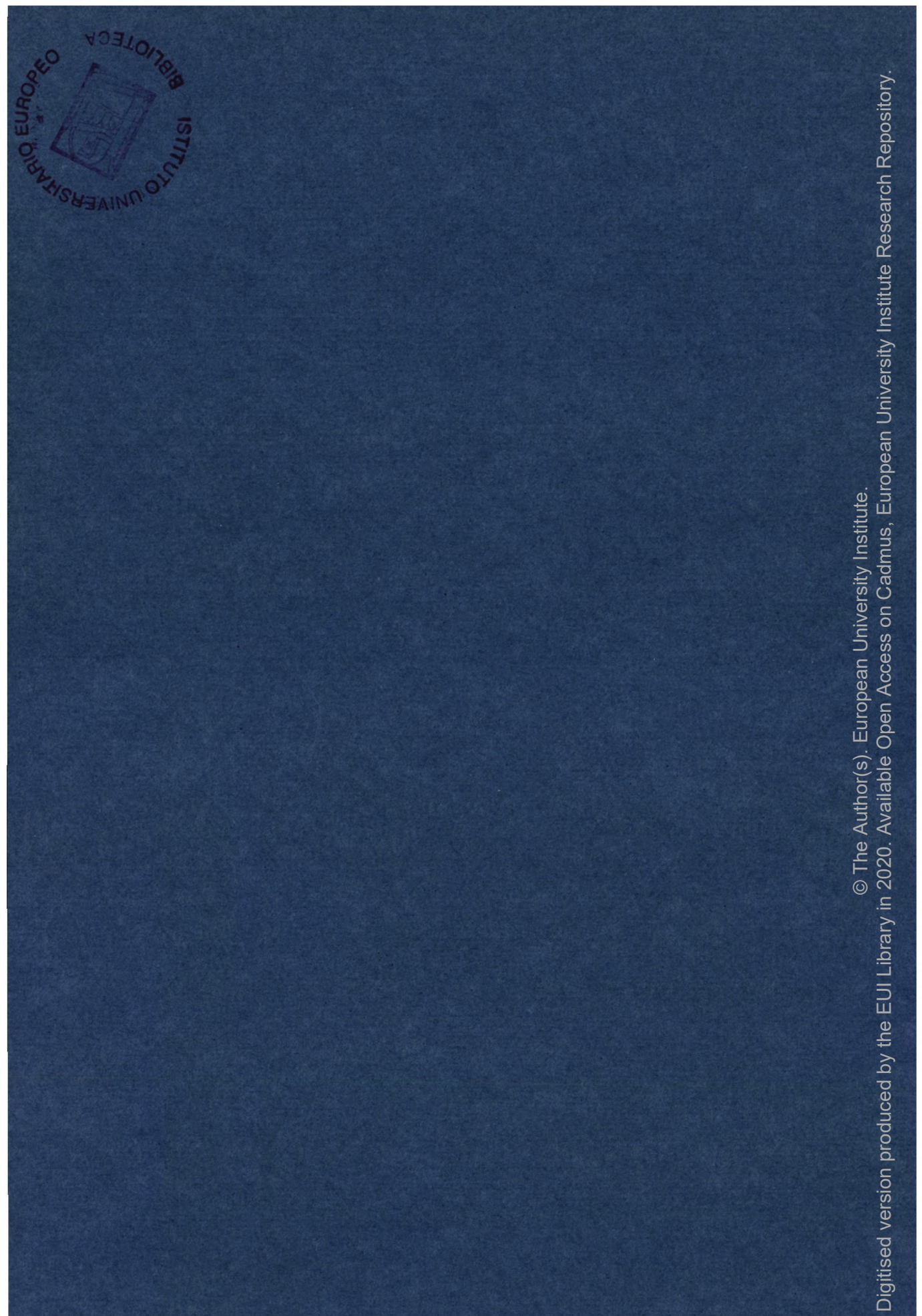

